\title{
Landscape scale social and ecological outcomes of dynamic angler and fish behaviours: processes, data, and patterns
}

\begin{tabular}{|c|c|}
\hline Journal: & Canadian Journal of Fisheries and Aquatic Sciences \\
\hline Manuscript ID & cjfas-2018-0168.R1 \\
\hline Manuscript Type: & Article \\
\hline $\begin{array}{r}\text { Date Submitted by the } \\
\text { Author: }\end{array}$ & 06-Jul-2018 \\
\hline Complete List of Authors: & $\begin{array}{l}\text { Carruthers, Thomas; University of British Columbia, Institute for the } \\
\text { Oceans and Fisheries } \\
\text { Dabrowska, Kornelia; Simon Fraser University Department of Biological } \\
\text { Sciences } \\
\text { Haider, Wolfgang; Simon Fraser University, School of Resource and } \\
\text { Environmental Management } \\
\text { Parkinson, Eric; University of British Columbia, Institute for the Oceans } \\
\text { and Fisheries } \\
\text { Varkey, Divya; Fisheries and Oceans Canada Newfoundland and } \\
\text { Labrador Region } \\
\text { Ward, Hillary; British Columbia Ministry of Forests Lands and Natural } \\
\text { Resource Operations } \\
\text { McAllister, Murdoch; University of British Columbia, Institute for the } \\
\text { Oceans and Fisheries } \\
\text { Godin, Theresa; Freshwater Fisheries Society of BC, Research Evaluation } \\
\text { and Development } \\
\text { van Poorten, Brett; BC Ministry of Environment, } \\
\text { Askey, Paul; Freshwater Fisheries Society of BC, } \\
\text { Wilson, Kyle; University of Calgary, Biological Sciences } \\
\text { Hunt, Len; Ontario Ministry of Natural Resources and Forestry, Centre for } \\
\text { Northern Forest Ecosystem Research } \\
\text { Clarke, Adrian; Freshwater Fisheries Society of British Columbia } \\
\text { Newton, Eric; University of Calgary, Biological Sciences } \\
\text { Walters, Carl; University of British Columbia, Institute for the Oceans } \\
\text { and Fisheries } \\
\text { Post, John; University of Calgary, Biological Sciences }\end{array}$ \\
\hline Keyword: & $\begin{array}{l}\text { FISHERY MANAGEMENT < General, SPATIAL ANALYSIS < General, } \\
\text { LANDSCAPE ECOLOGY < General, RECREATIONAL FISHERIES < General }\end{array}$ \\
\hline $\begin{array}{r}\text { Is the invited manuscript for } \\
\text { consideration in a Special } \\
\text { Issue? : }\end{array}$ & Not applicable (regular submission) \\
\hline
\end{tabular}

\section{SCHOLARONE Manuscripts}


Landscape scale social and ecological outcomes of dynamic angler and fish behaviours:

Thomas R. Carruthers ${ }^{1}$, Kornelia Dabrowska ${ }^{2}$, Wolfgang Haider ${ }^{2}$, Eric A. Parkinson ${ }^{1}$, Divya A. Varkey $^{1}$, Hillary Ward ${ }^{3}$, Murdoch K. McAllister ${ }^{1}$, Theresa Godin ${ }^{4}$, Brett Van Poorten ${ }^{1}$, Paul J. Askey $^{5}$, Kyle L. Wilson ${ }^{6}$, Len M. Hunt ${ }^{7}$, Adrian Clarke ${ }^{8}$, Eric Newton ${ }^{6}$, Carl Walters ${ }^{1}$ and John

$7 \quad$ R. Post ${ }^{5}$

$9{ }^{1}$ Institute for the Oceans and Fisheries, University of British Columbia, Vancouver, British

10 Columbia, Canada, V6T 1 Z4.

$11 \quad{ }^{2}$ School of Resource and Environmental Management, Simon Fraser University, 8888 University

12 Drive, Burnaby, British Columbia, Canada V5A 1S6

$13{ }^{3}$ Ministry of Forests, Lands, Natural Resource Operations and Rural Development. Penticton,

14 British Columbia, Canada. V2A7C8

$15{ }^{4}$ Freshwater Fisheries Society of British Columbia, University of British Columbia, Vancouver,

16 British Columbia, Canada, V6T 1 Z4

$17{ }^{5}$ Freshwater Fisheries Society of British Columbia, Summerland, British Columbia, Canada,

$18 \quad \mathrm{~V} 0 \mathrm{H} 1 \mathrm{Z1}$

$19{ }^{6}$ Ecology and Evolutionary Biology, Department of Biological Sciences, University of Calgary,

20 Calgary, Alberta, Canada T2N 1N4.

$21{ }^{7}$ Centre for Northern Forest Ecosystem Research, Ontario Ministry of Natural Resources and 22 Forestry, Thunder Bay, ON, Canada, P7E 2V6

$23{ }^{8}$ Freshwater Fisheries Society of British Columbia, Victoria, British Columbia, Canada, V9A $24 \quad 7 \mathrm{~S} 2$ 
Abstract

27 The first relatively complete landscape scale social-ecological system (SES) model of a recreational fishery was developed and ground-truthed with independent angling effort data. Based on the British Columbia multi-stock recreational fishery for rainbow trout, Onchorynchus mykiss, the model includes hundreds of individual lake fisheries, hundreds of thousands of anglers, originating from tens of communities, connected by complex road and trail networks, all distributed over a landscape of approximately half a million square kilometers. The approach is unique in that it incorporates realistic and empirically derived behavioural interactions within and among the three key components of the SES: angler communities, fish populations and management policies. Current management policies were characterized and alternate policies assessed by simulation. We examined spatial patterns in ecological and social properties of the of fish population productivity. dynamics 


\section{INTRODUCTION}

Spatially-structured consumer-resource systems exhibit complex and hierarchical dynamics that may be interpreted under the metapopulation paradigm (Wu and Loucks 1995; Hanski 1999; Sanchirico and Wilen 2005). This complexity and spatial hierarchy is particularly evident at the intersection of management, governance, and natural systems, i.e., social-ecological systems (SES) (Cash et al. 2006; Liu et al. 2007; Levin et al. 2013; McGinnis and Ostrom 2014; Arlinghaus et al. 2017). Obtaining accurate SES predictions can be difficult because consumers are mobile, resources are patchy, and the dynamics of the holistic system depends on the behaviour of many interdependent parts; this includes heterogeneous behaviour of humans (Liu et al. 2007) and metapopulation dynamics among a patchy resource landscape (Sanchirico and Wilen 2005). Despite these difficulties, SESs require a mechanistic understanding of the processes driving system dynamics to advise natural resource decision-making.

Theoretical frameworks have been developed that formally link bioeconomic, landscape, metapopulation, and social-ecological processes (Sanchirico and Wilen 1999; 2005; Ostrom 2009; Folke et al. 2010) to inform management of SESs. Such theory has guided development of models to predict patterns in resource exploitation based on a mechanistic understanding of human, ecological, and abiotic behaviour (Fulton et al. 2011; Walters et al. 1997; Cenek et al. 2017). Application of such mechanistic models has occurred frequently for marine fisheries but is less common in freshwater recreational fisheries (see examples: Post et al. 2008; Hunt et al. 2011).

SES models contain ecological, social and management (governance) components, which are linked by behavioural feedbacks (Ostrom 2010). Both terrestrial and aquatic SESs can be spatially-structured and spatially-managed (Synes et al. 2016). Hence, any SES model must 
explicitly capture the key processes that regulate these feedbacks and, as in any spatially complex system, also make credible predictions across space and time (Carpenter and Brock 2004; Sanchirico and Wilen 2005; Synes et al. 2016). Similarly to terrestrial environments, freshwater fisheries typically exhibit discrete spatial patchiness. While the population dynamics of freshwater and marine fisheries are similar (e.g. growth, reproduction, survival), both consumer behaviour (e.g., angler behaviour, preferences, and associated effort responses) and fish populations are generally easier to observe in freshwater fisheries than marine fisheries which often operate off-shore and over much larger geographic ranges. It follows that SESs for freshwater fisheries offer a bridge between marine and terrestrial case studies. Lastly, and of interest to many spatial ecologists, the dispersal processes in many inland fisheries are asymmetrical as the consumers (anglers) are comparatively more mobile than the resource (i.e., recreational anglers travel long distances while inland fishes are often precluded from large migrations).

It is increasingly recognised that managing recreational fisheries should consider the wider SES accounting for the complex interdependence between management measures, angler preference, fish population dynamics and the spatial distribution of anglers in relation to angling opportunities (Radomski et al. 2001; Post et al. 2008; Johnston et al. 2010; Hunt et al. 2011; Lester et al. 2014). The potential benefits of doing so include more appropriate measures of management performance (Carpenter and Brock 2004) and improved prediction of system responses to management measures (Cox et al. 2003; Beardmore et al. 2011; Arlinghaus et al. 2017). While previous SES models have included components for biological and human dimensions these have produced only simulated predictions of spatial angler effort and catch rates, for example. (Sanchirico and Wilen 1999; 2005; Post et al. 2008; Fulton et al. 2011; Hunt 
et al. 2011). Two primary obstacles in creating defensible, empirically derived SES models include the high data requirements (e.g. surveying anglers, lake monitoring of angling effort) and efficient computation of the predicted state of the system for a proposed management option (Synes et al. 2016). The latter is required to allow the SES model to be run iteratively when fitted to data but is challenging because recreational systems often include thousands of lakes and hundreds of thousands of anglers (e.g. Post et al. 2008; Hunt et al. 2011).

The aim of this research is to understand spatial SES outcomes given heterogeneity in human behavior, ecological dynamics, and management actions, and also spatial heterogeneity in resource abundance, resource quality, users and user access. We developed and tested this approach for the British Columbia rainbow trout (Oncorhynchus mykiss) recreational fishing landscape. This system offers an ideal case study due to the availability of robust fish population surveys and assessments for many lakes (see Parkinson et al. 2004; Askey et al. 2013; Wilson et al. 2016). Additionally, the system includes heterogeneity in angler behavior and preferences originating from multiple population centres (e.g., Ward et al. 2013a; b; Dabrowska et al. 2014; 2017) that can be used to characterize the ecological and social factors influencing SES dynamics across the landscape. Unlike previous SES modelling, we aimed to develop an SES model that could be fitted to empirical data.

A principal goal of the empirical SES modelling was to characterize the ecological outcomes (e.g. spatial fish density, spatial fishing pressure) and social outcomes (e.g. effort distribution, spatial distribution of angling utility, equity among angler classes) of current management interventions. An additional goal was to evaluate alternative management interventions of large increases in the stocking of particular lakes, increased stocking of lakes near population centres and the imposition of trophy fishing regulations in the form of new bag limits. 


\section{Methods}

117

118

119

120

121

122

\section{Fishery landscape}

Rainbow trout provide an important multi-stock recreational fishery to inland British Columbia, a landscape of approximately $500,000 \mathrm{~km}^{2}$ that includes over 4000 lakes of which nearly 600 are stocked annually with hatchery-raised wild-strain rainbow trout (Figure 1). This fishery landscape is highly connected with a complex road and trail network and hundreds of population centres.

The recreational fishery is managed by the British Columbia Provincial government and attracts about 2.5 million angler-days per year (DFO 2010) worth an estimated value of approximately US\$800 M per year (Bailey and Sumaila 2012). The primary management objectives as articulated by the British Columbia Provincial Government are to "conserve wild fish and their habitats" and to "optimize recreational opportunities based on the fishery resource". Measures of success associated with these objectives include angler satisfaction, fishing effort and license sales (MOE 2007).

Travel distance is one of the primary factors influencing fishing effort (Post et al. 2008). The road network in British Columbia is convoluted and there are multiple routes that can be taken from each population center to each fishing site. Least travel time distance was calculated among the centroids of lakes and population centres along paved, gravel and foot paths with spatial data extracted from the Digital Road Atlas of the British Columbia Geographic Warehouse (http://www2.gov.bc.ca/gov/content/data/geographic-data-services/bc-spatial-datainfrastructure/bc-geographic-warehouse). Least travel time for larger lakes was calculated for 
137 each access point, rather than the centroid of the lake, and the closest access point was used for

138 travel time calculations.

A range of management options are available for managing the British Columbia recreational trout fishery including size, number and species of stocked fish, fishing regulations (e.g. bag limits, boat engine restrictions), amenities (e.g. boat ramps, toilets, campsites) and access (e.g. footpaths, trails, paved roads). Currently, management decisions for British Columbia trout lakes are made primarily at the level of individual lakes and therefore these ignore a body of research on the ecology and angler behavior that suggests that management decisions, ecological processes and human behavior are interdependent over the wider landscape-scale (Cox et al. 2003; Carpenter and Brock 2004; Fenichel et al. 2013). For example, increasing the stocking rate of a particular lake may draw anglers away from other lakes due to higher expected catch rates (Post et al. 2008; Post and Parkinson 2012; Mee et al. 2016). An increase in angler density may also dissuade certain classes of anglers that now exploit opportunities at other lakes (Dabrowska et al. 2014; 2017). Because angler classes have varying fishing efficiencies (Ward et al. 2013b), catch rates, and therefore exploitation levels may be altered across a wider set of lakes. These changes in exploitation level may lead to changes in the growth rate and size composition of fish in these lakes (Walters and Post 1993; Askey et al. 2013; Ward et al. 2013b) and alter attractiveness for some angler classes (Aas et al. 2000). Because various classes of angler are not distributed evenly across British Columbia (e.g., casual anglers are most predominant in the urban centres of southern British Columbia, Dabrowska et al. 2014) improving angling opportunities in any given lake is likely to have an uneven benefit across angler classes. In this hypothetical scenario, a single management action has important wider consequences for both angling pressure over a wider range of lakes and equality of opportunity among anglers. 


\section{Overview of the S-SES model}

In this paper, we describe a novel landscape scale spatial SES model (referred to as the S-SES model herein) that brings together extensive research into the human dimensions of British

164 Columbia trout anglers (Dabrowska et al. 2014; 2017) with lake-specific biological models of

165 harvest compensation through density-dependent growth (Walters and Post 1993; Parkinson et al. 2004; Askey et al. 2013; Lester et al. 2014; Ward et al. 2017) (Figure 2). We validated the S-

167

The S-SES has three principal components to capture the processes that characterize the behavioral feedbacks and nodes of a generalized SES relevant to this and many other recreational fisheries:

(1) an angler behavior model that predicts the amount of angler effort on multiple lakes for multiple angler classes residing in multiple population centres;

(2) a biological model that predicts the impact of stocking rate options and fishing mortality rate on survival and growth of fish in each lake; and

(3) a numerical approach for converging on a stable distribution of angling effort over the landscape. 
At the heart of S-SES is a logit choice model that calculates angler effort $E_{A, p, l}$ as the number of days of fishing lake $l$, for a class of anglers $A$, residing in a population centre $p$ (Table 1 contains a summary of all model parameters, variables and indexes):

$$
E_{A, p, l}=m_{A} \cdot n_{A, p} \cdot \frac{G_{A, p, l}}{\tau_{A, p}+\sum_{l} G_{A, p, l}}=n_{A, p} \cdot \bar{E}_{A, p} \cdot \frac{G_{A, p, l}}{\sum_{l} G_{A, p, l}}
$$

where $m_{A}$ is the maximum number of days of effort in a year per angler, $n$ is the number of licenses sold, $\tau$ is the weight of not angling in the landscape of modelled lakes for individuals who have already purchased a license (which includes all other leisure opportunities including angling opportunities not modelled) and is specific to each management region $r, G$ is the weight of a particular lake, $\bar{E}$ is the mean effort (days per year) of an angler of class $A$ in population centre $p, E$ is the participation rate of anglers on each lake (days per year per license).

We used the right-hand expression of Eqn. 1 to fit a landscape model and calculate $G$ terms using data regarding mean effort $\bar{E}$. This formulation is designed to reallocate a fixed amount of effort $(n \times \bar{E})$. In order to predict increases in landscape-wide effort, it is necessary to move towards the formulation of the central expression that includes the $\tau$ term. Once $G$ terms are calculated it is simple to calculate the weight of not angling the landscape of modelled lakes $\tau$ :

$$
\tau_{A, p}=\frac{m_{A} \cdot \sum_{l} G_{A, p, l}}{\bar{E}_{A, p}}-\sum_{l} G_{A, p, l}
$$

Figure 1 illustrates the location and size of the population centres and 584 lakes included in the S-SES model (details of the lakes and population centres are included in Table 2 and S1: Tables 
S1-S3). The S-SES model was implemented in the statistical environment R (R Core Team 2017).

\section{Angler behavior}

Angler behavior was characterized by a latent class choice model (Swait 1994) based on hypothetical (stated) choices of British Columbia anglers. The model was based on utility maximization and random utility theories (Ben-Akiva and Lerman 1985) which assume that anglers choose fishing sites to maximize their well-being (utility). Following convention, utility for a fishing site was assumed to arise from a function of attributes that describe the trip such as catch rate and travel distance. Parameter estimates for attributes and attribute levels (e.g., a specific type of boat launch) were interpreted as preferences and the product of preferences and attributes provided a part worth utility for a fishing site. Heterogeneity among anglers was accounted for by the latent class part of the model and the observable trait of fishing license purchase fidelity. Here, we jointly estimated class-specific preferences for attributes and attribute levels and the probability that each angler would belong to a class (Swait 1994). A detailed assessment of several angler behavior model types, including the model used here, are presented in Dabrowska et al. (2017).

The choice for a responding angler was to select a fishing trip for rainbow trout to hypothetical lakes in British Columbia. Attributes and levels focused on both catch and noncatch related factors that are reported to affect fishing site choices by anglers (Hunt 2005; Dabrowska et al. 2017). Through pretests with British Columbia fisheries biologists, managers, and anglers, we selected four plausible levels for all attributes except for distance to the lake over paved road. Eight levels were selected for road distance given the broad range of travel distances 
225 from all angler population centres to all lakes across the landscape (Post et al. 2008). Pretests

226 revealed that anglers from the Lower Mainland Region (i.e. Vancouver) would normally travel

227 further than would other anglers and consequently, the attribute levels for paved distance were

228 specific to the angler origin.

229 A total of 96 choice sets were developed from a fractional factorial design. Each choice set

230 included three alternative fishing experience options: Lake A, Lake B, and neither Lake A nor

231 Lake B. This design was used to populate attribute levels for Lake A and Lake B alternatives in a

232 way to estimate all main effects (preferences for the attributes) independently from one another.

233 A random sample of British Columbia licensed anglers was drawn in two ways. First, 10,000

234 anglers were randomly selected and contacted who had previously provided e-mail addresses to

235 the Province of British Columbia. Second, another 2,500 anglers were randomly drawn and

236 contacted by mail. Each respondent was asked to complete a longer questionnaire (see

237 Dabrowska et al. 2014; 2017 for details) that included six choice sets. For each choice set,

238 respondents were asked to select Lake A, Lake B or neither Lake A or B for a day fishing trip.

239 For respondents who had reported fishing for multiple days in the previous year, we presented

240 the choices for both day and multiple day contexts because trip duration influences fishing site

241 preferences (Hunt et al. 2011).

242 A total of 2,848 on-line and 597 mail survey responses were obtained for an effective

243 response rate of $28 \%$. Only individuals targeting rainbow trout and/or kokanee in non-urban,

244 lake settings in the past year were asked to complete the choice tasks. This requirement reduced

245 the sample size to 2,106 individuals from which complete choice set responses were made by

2461,854 individuals and 2,763 day and multiple day contexts. 
The latent class choice model was selected in two steps. First, anglers who had not purchased a fishing license every year from 2005 to 2010 were separated from the sample and a simple conditional logit model was fitted to uncover preferences for the attributes and levels. For the remaining sample $(77 \%)$ of committed fishers (i.e. ones purchasing a license every year between 2005 and 2010), a latent class choice model was fitted. We selected three latent classes along

252 with the one known class for a total of four classes for the model. Although an Akaike Information Criterion (AIC) provided support for models with more than four classes, models with more than four classes exhibited non-sensible parameter estimates such as a preference for fishing sites with lower catch rates, ceteris paribus. Given that no standard approach exists for model selection for latent class choice models (Provencher and Bishop 2004), our choice of three

257 latent and one known class was guided by both information statistics and the validity of the parameter estimates obtained.

We focused on six attributes to guide fishing site choice by anglers: lake distance $(d)$; expected catch rates $(C)$; expected size of fish caught $(S)$; angler crowding $(X)$; a set of categorical lake attributes $(H)$, that included boat launch facilities, engine restrictions, the stocked species of fish and the take limit (the number of fish that may be caught and killed per day); and finally lodging and accessibility $(W)$. The utility for any fishing site was determined 264 from:

(3) $\log \left(G_{A, p, l}\right)=f\left(d_{p, l}, \ldots\right)+f\left(C_{A, l}, \ldots\right)+f\left(S_{l}, \ldots\right)+f\left(X_{l}, \ldots\right)+f\left(H_{l}, \ldots\right)+f\left(W_{l}, \ldots\right)$

Attributes 1-4 of the S-SES model (lake distance, expected catch rates, expected size of fish, 
270 linear relationships from the latent class choice model (Figure 3). In the case of expected catch

271 rates, we used a non-linear relationship to extrapolate preferences for catch rates beyond the

272 range of attribute levels that we presented to the survey respondents. This decision to alter the

273 relationship was informed by increasing evidence that expected catch rates have a strong yet

274 diminishing effect on fishing site choice (Arlinghaus et al. 2014) and angler satisfaction or well-

275 being (Beardmore et al. 2015). Therefore, utility $U$, was assumed to follow a non-linear

276 relationship with expected catch rate $C: U=a C^{b}+d$ (Figure 3, panel b). A single metric of access

277 and lodging was developed and the S-SES model was then fitted to observations of angling

278 effort.

279 We labelled the four classes as occasional anglers (the known class), generalists, social 280 anglers, and enthusiasts that represented 23, 36, 24, and 17\% of the sample, respectively (see

281 Figures 3 and 4). The site choice decisions for occasional anglers were least influenced by the

282 expected size of fish and were most negatively influenced by any fly-fishing regulation instead

283 with class members strongly preferring a barbless hook only or no gear regulation. Generalists

284 were responsive to all lake characteristics sensitive to expected size of fish, possession limit, and

285 travel distance affecting their fishing site choice. Site choices were, however, strongly negatively

286 influenced by fly fishing only regulations and crowding by other anglers. Social anglers

287 preferred fishing sites with more anglers and larger-sized lakes. Despite their label, social

288 anglers placed greater importance on take limits of fish than did most other classes of anglers.

289 The final class of anglers, enthusiasts, showed a very strong preference for sites with larger

290 expected sizes of fish and those allowing fly fishing only. Like the occasional anglers, the

291 enthusiasts were more sensitive to the effects of travel distance than were anglers from other

292 classes. 
Besides the catch and non-catch traits of individual lake fisheries to which the heterogeneous angler population responded, we estimated differential catchabilities for angler groups using a discriminant function analysis and observations from Ward et al. (2013a; b). Survey respondents were assigned to the four angler clusters developed in Ward et al. (2013a), based on three variables: distance traveled, harvest to catch ratio and catchability. Individual angler catchability was estimated as a function of angler experience (days fished per year) based on the parameters in Ward et al. (2013b).

\section{Biological processes}

302 Somatic growth was assumed to follow a bi-phasic model that accounts for energy allocation 303 before and after maturation (Lester et al. 2004). In the first phase the model approximates 304 juvenile growth linearly according to a growth rate $h\left(\mathrm{~mm} \cdot \mathrm{yr}^{-1}\right)$ that varies with climate and the 305 density of fish. In the second phase adult growth was approximated by an asymptotic von 306 Bertalanffy model (see Table 3 for details). In this model, natural mortality shaped known 307 energetic trade-offs between growth and reproduction (see $L^{\infty}, t_{0}$ and $K$ below), and natural 308 mortality was calculated based on allocation of energy to reproduction as parameterized by Ward et al. (2017).

310 Fish population density was modelled as the effective density $D\left(10^{-6} \mathrm{~mm}^{2} \mathrm{ha}^{-1}\right)$ of fish in a 311 particular lake $l$ of all stocking types $T$ (e.g. fry, catchables) calculated by:

$$
D_{l}=\frac{\sum_{T} \sum_{a} N_{l, T, a} \cdot L_{l, T, a}{ }^{2}}{\left(10^{-6} \cdot v_{l}\right)}
$$


315 where $N$ is the predicted number of fish at stocking at age $a, L$ is the predicted length of fish

$316(\mathrm{~mm})$ and $v$ is the surface area of the lake (ha). Both growth phases depended on lake

317 productivity according to the annual growing degree days $\hat{G}$. Annual growing degree days are an

318 index of thermal energy and are correlated with fish growth rates (Neuheimer and Taggart 2007;

319 Ward et al. 2017). Growing degree days were estimated based on latitude, longitude, and

320 elevation data based on ClimateBC v5.10 program developed by Wang et al. (2015). For any day

321 of the year, growing degrees are the number of degrees Celsius over a threshold level of $5^{\circ} \mathrm{C}$

322 necessary for growth (Lester et al. 2014). The annual growing degree days $\hat{G}$, is the summation

323 of these growing degrees over a year. Thermal age $Q$ (expected number of growing degree days

324 experienced by a given age class $a$ in units of 1000 days) was calculated as:

$$
Q_{l, a}=\frac{1}{1000} \cdot \widehat{G}_{l} \cdot(a-0.5)
$$

For each stock type $T$, the biphasic model described the change in length at age $L_{a}(\mathrm{~mm})$ between

329 juvenile and adult growth occurring when the thermal age $Q$ of age class $a$ exceeded the thermal 330 age at maturation $Y$ such that:

$$
L_{l, T, a}=\left\{\begin{array}{cc}
L_{l, T}^{\infty} \cdot\left(1-\exp \left(-K \cdot\left(Q_{l, a}-t_{0, l}\right)\right)\right) & Q_{l, a}>Y_{l, T} \\
h_{l, T} \cdot Q_{l, a}+L_{s, T} & Q_{l, a} \leq Y_{l, T}
\end{array}\right.
$$

$$
Y_{l, T}=\gamma \cdot h_{l, T}{ }^{-\delta}
$$


336 where $\gamma$ and $\delta$ are shape parameters which describe how age, juvenile growth, and degree days

337 influence thermal age at maturity (Table 3$), L_{s}$ is the length at the time of stocking $(\mathrm{mm})$.

338 Density-dependent juvenile growth $h\left(\mathrm{~mm} \mathrm{yr}^{-1}\right)$ was calculated as:

340

$$
h_{l, T}=\Delta \cdot L_{s, T}^{\beta} \cdot e^{\alpha \cdot D_{l}} /\left(10^{-3} \cdot \widehat{G}_{l}\right)
$$

where $D$ was the effective density of fish $\left(10^{-6} \mathrm{~mm}^{2} \mathrm{ha}^{-1}\right.$, Equation 3$)$ and the parameters $\alpha, \Delta$ and $\beta$ were shape parameters for density-dependence (Table 3). dependent such that:

$$
L_{l, T}^{\infty}=3 \cdot h_{l, T} / g_{T}
$$

$$
t_{0, l, T}=Y_{l, T}+\ln \left(1-\frac{g_{T} \cdot\left(h_{l, T} \cdot Y_{l, T}+R_{T}\right)}{3 \cdot h_{l, T}}\right) / \ln \left(1+g_{T} / 3\right)
$$

The slope of growth at the origin $K\left(\mathrm{~mm} \mathrm{y}^{-1}\right)$ was assumed to be determined by the proportion of surplus energy allocated into reproduction $g$ (Table 3):

$$
K_{T}=\ln \left(1+g_{T}\right) / 3
$$

In order to predict numbers, it was necessary to calculate total fraction of fish removed by 


$$
R_{l, T, a}=\sum_{p} \sum_{A}\left(\frac{E_{A, p, l}}{365 \cdot v_{l}} \cdot q_{A} \cdot s_{a}\right)
$$

where $s$ is the selectivity at age $a$, the catchability coefficient $q\left(\right.$ ha $\left.\mathrm{d}^{-1}\right)$ is specific to each angler cumulative Poisson distribution:

$$
\Phi_{A, l}=1-\left(e^{-C_{A, l}}\left(1+\sum_{j=1}^{\left\lfloor B_{l}\right\rfloor} \frac{C_{A, l}{ }^{j}}{j !}\right)\right)
$$

where \lfloor\rfloor is the floor function.

The total fishing mortality rate accounting fish released due to exceeding the bag limit $\Phi$, those released voluntarily $V$ and those that die after release $\psi$ was calculated:

$$
F_{l, T, a}=(1-\mathrm{V})\left(1-\Phi_{A, l}\right) R_{l, T, a}+\left(1-(1-\mathrm{V})\left(1-\Phi_{A, l}\right)\right) R_{l, T, a} * \psi
$$

Total mortality rate $Z$ that includes natural mortality rate $M$ (Table 3 ) was given by:

$$
Z_{l, T, a}=F_{l, T, a}+M_{T, a}
$$
numerical optimization. 
For any lake, expected numbers at age for a given stocking type $T$, and age $a$, could then be calculated according to the stocking numbers $N^{0}$ :

$$
N_{l, T, a}=N_{l, T}^{0} \cdot \exp \left(-\sum_{i=1}^{a-1} Z_{T, i}-\frac{Z_{T, a}}{2}\right)
$$

\section{Three of the central variables in the effort prediction model of Eqn. 3 are expected catch rates} by angler class $C$ (fish ha ${ }^{-1} \mathrm{~d}^{-1}$ ), expected size of fish caught $S$ by lake (mm) and angler crowding $X\left(\right.$ anglers $\left.\mathrm{ha}^{-1}\right)$ by lake $l$. These were given by:

$$
C_{l, A}=\sum_{T} \sum_{a} N_{l, T, a} \cdot v_{l}^{-1}\left(1-\exp \left(q_{A} \cdot s_{a}\right)\right)
$$

$$
S_{l, A}=\sum_{T} \sum_{a} N_{l, T, a} \cdot L_{l, T, a}\left(1-\exp \left(q_{A} \cdot s_{a}\right)\right) / C_{l, A}
$$

$$
X_{l}=\sum_{A} \sum_{p} E_{A, p, l} /\left(365 \cdot v_{l}\right)
$$

\section{Numerical approximation to the ideal free distribution of angling effort}

$$
\text { For a given set of management options, we calculated the predicted distribution of angling }
$$

effort on the landscape such that for any class of anglers in each population centre, a change in distribution led to homogenization of overall utility. This state is referred to as the Ideal Free Distribution (IFD) of angling effort where no additional increase in utility is possible by anglers moving to alternate lakes in which to fish (Kennedy and Gray 1993; Parkinson et al. 2004; Askey et al. 2013). 
To calculate the IFD of angling effort, we started with an initial calculation of effort $E_{1}$ for each lake that was the same as Eqn. 1 but was calculated using the weight terms $G$, without accounting for the predicted size and catch rate of fish on each lake (the $S$ and $C$ terms of Equation 3, respectively). This initial effort distribution $E_{1}$, allows fishing mortality rate to be calculated and hence, it is possible to obtain the initial predictions of expected size of catches $S$, and catch rate $C$. This initialization enables the calculation of the full weight term $G$ including utility components for $S$ and $C$, and hence an updated predicted effort distribution, $E_{l}{ }^{\text {trial }}$. The next calculation of effort $E_{2}$, is based on a weighted combination of the previous effort distribution $E_{1}$, and its update $E_{l}{ }^{\text {trial }}$ with the degree of relaxation determined by the parameter $\theta$ :

$$
E_{i}=(1-\theta) \cdot E_{i-1}+\theta \cdot E_{i-1}^{\text {trial }}
$$

When operating correctly, this numerical procedure may be iterated until convergence on an approximation to the IFD of effort has been achieved $\left(E_{i} \approx E_{i-1}\right)$. We define successful convergence when the effort of all angler classes from all population centres on all lakes $\left(E_{A, p, l}\right.$, Equation 1) are all within half an angler day of the previous iteration. Our SES model reliably converged within 200 iterations given a $\theta$ value of 5\%. This value was sufficient to calculate a stable solution within a few seconds enabling the model to be used iteratively, for example, in numerical optimization of parameters to fit observed effort data. This iterative approach (a relaxation method), is required to prevent oscillation in predicted effort or 'flip-flopping' between alternate states. Figure 5 shows the convergence to a numerical approximation of the IFD of angling effort for the SES model given different values of $\theta$; panel d shows the oscillation phenomenon at high $\theta$ values. 
As illustrated by Figure 5, the value of $\theta$ determines the trade-off in convergence speed (number of iterations to reach 'convergence') against angling effort instability. Unfortunately, there are no general rules for selecting an appropriate level of $\theta$ because convergence depends on the configuration of the particular landscape. For example, it is possible to describe a landscape in which there are two population centres composed of similar proportions of angler classes that are approximately equidistant from the lakes in the model. It follows that effort from the anglers of one population centre are interchangeable with effort from anglers of the other population centre and thus the problem is poorly defined and highly unstable requiring very low values of $\theta$. Note that the predicted total effort on a modelled lake may be stable while the effort from each population centre and angler class are perfectly traded-off and are therefore, unstable.

\section{Simplifying the landscape of anglers and fitting to data}

As described above, it is necessary to have contrast in the location of population centres and lakes to calculate a stable approximation to the IFD of effort. The most complex landscape model included 24 population centres some of which are situated near each other. In such a case, the effort from one population centre would be confounded with that of the adjacent population centre and it would not be possible to calculate a stable IFD of effort. To address this problem, population centres were clustered to ensure that they were distinct relative to the landscape of lakes. Firstly, a dissimilarity matrix $\Omega$ was calculated to capture the difference among the population centres in their location relative to the landscape of lakes.
$(21)$

$$
\Omega_{p, \bar{p}}=\sum_{l}\left|d_{p, l}-d_{\bar{p}, l}\right|
$$


449 This definition of dissimilarity is more appropriate than simply using the geographic distance 450 among population centres as it accounts for travel distance and is therefore considerate of both 451 the distribution of lakes and the configuration of the British Columbia road network. The 452 hierarchical cluster analysis function 'hclust' (of the 'stats' R package) was then used to group population centres into 9 clusters using Ward's criterion (Murtagh and Legendre 2014) (S1:

Figure S1). When combined, the attributes of the clustered population centres were either summed (e.g. angler numbers) or calculated as weighted mean according to angler numbers in component population centres (e.g. distance to lakes).

There were two stages to the process of model fitting. We divided the landscape model into two sets of lakes: a training set and a British Columbia-wide set (Figure 1). The training set was made up of 34 lakes that were subject to recent experimental manipulations (Mee et al. 2016) for which we have a wider selection of high quality data available. The British Columbia-wide set includes these lakes and a further 550 (584 in total) over a much wider spatial range that have fewer covariate data and less precise observations of angling effort.

We initially fitted the model to observations of effort for the training set to estimate two parameters that were not available from the angler behavior or biological model components: the mean release rate of captured fish by catch-and-release anglers $V$ (Eqn. 14), and the slope in angler utility relative to lodging and access $\kappa$. The utility component for lodging and access (Equation 3) was calculated:

$$
f\left(W_{l}, \kappa\right)=\kappa \cdot W_{l}
$$

where the access and lodging covariate $W$, for each lake $l$, was calculated as: 


$$
W_{l}=\exp \left(-\frac{\text { gravel }_{l}}{55}-\frac{4 W D_{l}}{15}-\frac{\text { foot }_{l}}{3}\right) \cdot\left(\text { campsites }_{l}+\text { lodgebeds }_{l}\right)
$$

474

475

476

(1)

where gravel is the distance $(\mathrm{km})$ to the lake on a gravel road, $4 W D$ is the distance to the lake on a rough off-road surface and foot is the distance to the lake by footpath only (these are divided by 55,15 and 3, which represent the expected average speed of travel on these surfaces; $\mathrm{km} \mathrm{hr}^{-1}$ ). Following applications that have predicted recreational fishing activity (e.g., Drake and Mandrak 2010; Muirhead and MacIssac 2011), we multiplied the non-linear effect travel (time) by site attractiveness, which we defined as the sum of campsites and lodge beds at each lake.

To fit the model, observed annual effort at a lake $E^{o b s}$ was assumed to follow a lognormal observation error model with a standard deviation of 0.5 . The objective function $O B J$ to be minimized was the negative log-likelihood:

(24)

$$
O B J=\sum_{l} 2 \log (0.5)+\left(\log \left(E_{l}^{o b s}\right)-\log \left(E_{l}^{\text {pred }}\right)\right)^{2}
$$

Predicted total effort on a lake $E^{\text {pred }}$ was simply model predicted effort summed over angler classes and population centres:

$$
E_{l}^{\text {pred }}=\sum_{A} \sum_{p} E_{A, p, l}
$$

The maximum likelihood estimates of the mean release rate $V$, and the slope in log utility with lodging and access $k$, were 0.83 and 1.15 respectively. 
495

496

497

498

499

500

501

502

503

504

505

506

507

508

509

510

511

512

513

514

515

516

517

\section{ReSUltS}

\section{Fit to experimental data}

The S-SES model fitted observed effort well for the training set of lakes $\left(R^{2}=0.979\right)$ and for the British Columbia-wide lakes set $\left(R^{2}=0.871\right)$ (Figure $\left.6 \mathrm{~b}\right)$. The greater variance in the British Columbia-wide lake set is expected as we lack data on access and lodging for this broader data set, and the observations of effort are less precise. Of the training set of lakes, one lake, Roche Lake, attracted the most angling effort. It was important to fit this lake correctly as a failure to do so could erroneously redistribute a large amount of effort onto or away from other nearby modelled lakes. The model exhibited a general tendency to over-estimate effort for small lakes at the edges of the landscape such as Teardrop Lake (Figure 6b), which is amongst the most northerly of the training lake set. Conversely the model tended to underestimate the effort on small lakes closer to the centre of the landscape such as Pratt Lake (Figure 6). There are several possible explanations for this that point to a limitation of the S-SES. Smaller distant lakes, such as Teardrop Lake, may often have restricted fishing seasons and are surrounded by other fishing opportunities that are not accounted for by the landscape model. In this situation, we would expect to overestimate effort compared to realized effort. This apparent attenuation is a limitation of our logit choice model and the spatial configuration of our landscape model.

\section{Non-independence in effort redistribution}

A principal advantage of the S-SES model is that it can predict instances where altering the angling quality of a single lake leads to reallocation of effort among lakes on the landscape. To demonstrate these spatial dynamics, we arbitrarily doubled the stocking rate of three lakes, including a high effort southern lake and a low effort northern lake (Figure 7c), and calculated 
518 the movement of effort among local lakes (Figure 7a, b, d). The magnitude of effort

519 redistribution varied considerably among the three experimental lakes (according to their size,

520 landscape location and current stocking rate), but in all three cases much of the redistributed

521 effort originated from a small fraction of relatively nearby lakes. The magnitude of the absolute

522 effort response to doubling stocking rates was related to lake size, with the greatest increase in

523 Sheridan Lake (1650 ha surface area), smallest in Kestrel Lake (58 ha) and intermediate in

524 Roche Lake (162 ha). The proportional increase in effort was greatest in Kestrel Lake suggesting

525 that this area has the greatest latent demand for fishing opportunities created by the simulated

526 stocking rate increase, and lower but similar demand in the other two areas. The stocking rate

527 doubling had the greatest improvement in fishing quality, as represented by catch rates, for

528 Sheridan Lake and its surrounding donating lakes. This outcome makes sense because a stocking

529 rate doubling on a large lake has a greater local and regional scale response simply because it

530 represents a greater infusion of fishing opportunities than does a doubling of stocking rate on a

531 small lake. The impact of doubling stocking rates on the smaller lake had lower impacts on

532 donating lakes, in proportion to the lakes size receiving the augmentation. Overall, increasing

533 stocking rates appear to have diminishing returns in terms of both effort and fishing quality due

534 to the dynamic spatial effort response (i.e. doubling stocking does not double effort or quality),

535 but is expected to increase both. This effect is strongest in the enhanced lake, but also felt in

536 adjacent lakes which experience a reduction in their effort due to the local redistribution of

537 anglers to the enhanced lake. This decline in local effort is manifest in an increase in quality as

538 local harvest is reduced. But, keep in mind that these simulations characterize a redistribution of

539 effort in response to increased fish availability, but do not address the question of whether we 
would expect an overall regional increase in effort in response to increased investment in enhanced hatchery capacity.

\section{Ecological outcomes across the landscape}

The landscape patterns of fish density and size are an outcome of the status quo stocking rates (S1: Table S1), landscape patterns of environmental conditions (as measured as growing degree days), and the spatial distribution of lakes and anglers (Figure 1). These spatial patterns and dynamics result in a characteristically non-homogeneous distribution of angler effort across the landscape (Figure 8a). Catch rates, as a measure of fish abundance, varied threefold, from a low in the Lower Mainland Region to the highest in the Cariboo Region (Figure 8b). Fish abundance is determined in these lakes by stocking and harvest rates. Harvest rates are a function of landscape characteristics: human abundance, angler participation rates, lake area and accessibility. Therefore, the emergent spatial pattern is due to management decisions on stocking rates, the movement of anglers from origins to lakes based on accessibility, the dynamic interaction between fish populations, harvest, and angler preferences for both catch and noncatch attributes of individual lakes. Not only do the regions differ in mean abundance of fish and lakes, but there is substantial difference in variability in abundance in regions. All regions have some lakes supporting only low densities but few have lakes supporting high fish densities. For example, the Lower Mainland region has no lakes supporting high abundance (i.e. a catch rate of more than 0.3 fish per hour), whereas the Kootenay, Thompson and Cariboo regions have many lakes with higher densities of fish. Other regions have intermediate variability among lakes and intermediate fish abundance. 
Mean size of fish in lakes also varies across the landscape. This population characteristic is a function of density-dependent fish growth, which is determined by the combination of management decisions on stocking rates, geographic patterns in growing degree days and harvest rates that modify abundance and size structure. The landscape pattern across the region (Figure $8 \mathrm{~b})$ shows a strong negative correlation between fish abundance and mean size $(r=-0.76, n=8)$ suggesting that density-dependent ecological processes dominate.

\section{Social outcomes across the landscape}

Perhaps not surprisingly, the model predicts the highest angling effort on lakes that are adjacent to the largest population centres, represented by the Abbotsford population centre (the British Columbia Lower Mainland region including the City of Vancouver) (Figure 9a). The Lower Mainland region has the lowest participation rate $(2.7 \%$ - per capita license sales $)$ but $72 \%$ percent of the population of British Columbia resulting in $42 \%$ of the total provincial license sales. The majority of the highest effort lakes are within approximately $300 \mathrm{~km}$ of the Lower Mainland region (see Figure 3C where these travel distances have positive part worth utilities). These south-central regions also have several intermediate-sized cities, Kamloops, Kelowna and Penticton (Figure 1) with much higher per capita participation rates (12.0\%) than in the Lower Mainland. More northerly lakes, despite being in regions with higher per capita participation, have much lower human population density and are prohibitively distant for most non-local anglers (see Figure 3c where travel distances greater than $300 \mathrm{~km}$ have negative part worth utilities).

The numerical response of the angler population to spatial variation in the availability of fishing opportunities, as linked dynamically through harvest, varies substantially across the 
fishery (Figure 9a). Clearly, most angling effort in British Columbia emanates from the Lower Mainland (as characterized by Abbotsford) where despite low participation rates the population is high and within $300 \mathrm{~km}$ of abundant opportunities. The second greatest fishing effort emanates from the Thompson and Okanagan regions (characterized by Kamloops) where the population is substantially lower but participation rate is high and there is an abundance of short distance angling opportunities (Figure 9a).

The angler population is not homogeneous in its behavior (Figure 9a). Overall, enthusiast anglers spent the greatest amount of time angling across all regions. The utility of the best fishing opportunities varies widely by region (Figure 9b) where anglers living in central areas enjoy the best quality of angling by some margin (i.e. Kamloops, Cariboo Rural, Prince George). Anglers from the Lower Mainland region, as characterized by anglers living in Abbotsford, spend the least time fishing and have few local lakes, requiring commuting several hundred kilometers to the central regions (reflected by low regional utility even for the top 20 lakes, Figure 9b).

\section{Spatial patterns in efficacy of management interventions}

A common management response to complaints of poor angling quality is increased stocking by management agencies (Post et al. 2002; Arlinghaus and Mehner 2005). To identify spatial patterns in stocking opportunities, 584 landscape models were run, one for each lake, where each lake in turn was subject to a $10 \%$ increase in stocking rate. In each case the landscape-wide effort response relative to the stocking cost was calculated (Figure 10). In some cases, the increased stocking attracted proportionally more effort for each dollar spent on stocking (the dark grey points, Figure 10). In other cases, the effort response did not appear to justify the additional 
608

609

611

612

613

614

615

616

617

618

619

620

621

622

stocking cost (white points, Figure 10). A positive change in fishing effort per dollar cost of stocking implies that the increased stocking improved the fishing quality, which is a combination of fish abundance and size as preferred by the aggregate angler population that are willing to travel to that particular lake. A negative change in effort with increased stocking implies that the ecological process of density-dependent growth results in reduced fish size and therefore, attractiveness of the fishery. The overall spatial pattern in effort response to stocking alteration is a function of the status quo stocking rates, processes involved in fish growth (density and growing degree days) and the latent demand for fishing opportunities of anglers willing to travel to particular lakes and their preferences for fishing quality. Therefore, in some cases the money spent on increased stocking might be better spent elsewhere; the effort response relative to increase in stocking costs may not be favourable for management. In general, increasing the stocking of the central lakes closest to communities was most likely to be cost-effective. But, across regions on the landscape there were no clear spatial patterns or gradients in stocking opportunities suggesting that management strategies may not be easily generalized at the scale of the whole fishery. This conclusion implies that considering how best to allocate stocking resources needs to be done at the regional scale, rather than a reallocation among regions. We next examined policy options at the within region spatial scale and assessed equality among angler groups at lakes of two types; near urban centres (within $100 \mathrm{~km}$ ) and distant to urban centres (greater than $100 \mathrm{~km}$ ) (Figure 11a). In the first example of a management action, we examined the consequences of a $10 \%$ increase in the stocking of lakes closer than $100 \mathrm{~km}$ travel distance to a major urban centre (Figure 11b). In general, effort of all angler classes was increased, but the margin of increase was much higher for occasional anglers located in Prince George and rural Cariboo. In some cases, angler effort was fractionally reduced, for example, 
631 social anglers in Fort St John. Because only two lakes were deemed to be within $100 \mathrm{~km}$ of an

632 urban centre, effort was moved away leading to a reduction in angling quality for the social

633 angler class that responds positively to increased angler densities. Increasing the stocking of

634 lakes within $100 \mathrm{~km}$ of an urban centre led to very small increases in angling effort for the Lower

635 Mainland area. The contrasting management option, a 10\% stocking rate increase on lakes

636 further than $100 \mathrm{~km}$ from an urban centre, led to a very different pattern of effort increases, with

637 almost no gains in Prince George and rural Cariboo (Figure 11c). Effort was only increased in a

638 few cases such as occasional anglers in rural Skeena and enthusiast anglers in Nelson.

639 Most current regulations impose a maximum bag limit of 5 fish per day. On some lakes,

640 sometimes referred to as "trophy" lakes, bag limits are lower, typically 2 fish per day or catch

641 and release only. To investigate the potential impacts of increasing the number of trophy lakes,

$64220 \%$ of lakes with an existing bag limit regulation of 5 fish per day were changed to a 2 fish per

643 day bag limit (90 lakes in total). The most likely candidates for trophy lake regulations are

644 productive lakes. Rather than arbitrarily selecting lakes for trophy regulation, the 90 lakes with

645 the highest growing degree days were selected (Figure 12a). The increased number of trophy

646 lakes generally increased effort, particularly for occasional anglers in Prince George, Cranbrook

647 and Nelson, and enthusiast anglers in rural Cariboo (Figure 12b). The only substantial reduction

648 in effort (-7\%) was seen for social anglers in Fort St John.

649

650 DiscuSSION

651 Multi-stock recreational fisheries provide an excellent subject for the study of spatial social-

652 ecological systems. The outcomes of the interactions among fish populations, fishers and

653 managers are governed by behavioral interactions overlain on the spatial landscape of the fishery 
654 (Ward et al. 2016; Arlinghaus et al. 2017). Processes occurring within and among these three 655 players in the S-SES occur at a diversity of spatial scales, over a range of temporal scales, are often complex and non-linear, and their dynamic outcomes are difficult to predict. To assess these social-ecological outcomes, we presented a dynamic model of the key behavioral processes across a large empirical landscape of fish populations, a behaviorally diverse angler community and alternate policy options. Although built and parameterized for a particular fishery and its landscape, the qualitative dynamic outcomes should be generalizable to other spatially-structured recreational fisheries, which are common in many parts of the world (Post et al. 2002; Allan et al. 2005; Arlinghaus et al. 2017).

Previous models for predicting spatial patterns in angling effort have assumed that lakes are independent (Cox and Walters 2002; Post et al. 2008; Post and Parkinson 2012). Approaches that account for non-independence in angling effort among lakes have concluded that ignoring this phenomenon could lead to poor management decisions over a wider spatial scale (Cox et al. 2003; Hunt et al. 2007; 2011). Our S-SES model addresses shortcomings of previous approaches by accounting for the complex interplay of management options, angler choice, density dependent growth of fish and the spatial distribution of anglers and angling opportunities. The model provides predictions of landscape-wide effort distributions that matched independent empirical observations reasonably well (Figure 6). Therefore, we believe that the model could reliably be used to simulate and assess alternate management policy options.

Ecological dynamics in this S-SES occur at the lake (or patch) scale where fish recruitment, growth and survival are locally determined, and in aggregate these define the production available for harvest across the landscape. Our modelled system was somewhat simplified; we bypassed the complexities involved in natural recruitment by using stocked fisheries. We 
677 however retained the important in-lake ecological functions of density- and climate-dependent 678 growth and survival, which are key sources of compensation in the dynamics of harvest (Lester et al. 2014; Ward et al. 2017). At the landscape scale, nutrient richness and climate variables interact with lake scale density-dependence to control fish production.

Social dynamics in this S-SES are complex because there is substantial heterogeneity among anglers with behavior modified by both catch and non-catch-related attributes (Hunt 2005). In addition, landscape heterogeneity in angler population abundance, participation rates, distribution of behavioral types and transportation networks result in substantial spatial heterogeneity of harvest demand by anglers across a fishery (e.g., Carson et al. 2009). Following convention, we used random utility and utility maximization theories to predict angler distribution across the landscape (e.g., Abbott and Fenichel 2013). We also observed an approximately two-fold variation among angler groups in both catchability and maximum annual fishing days. Therefore, angler harvest behavior, which is determined by their efficiency and maximum effort, differentially impacts harvest mortality and resulting feedback processes in the modelled system as has been demonstrated empirically (Johnston et al. 2013; Ward et al. 2016). The management component of the S-SES was not dynamically linked to the ecological and social processes in our simulations. For simplification, we started with a fixed status quo for the empirical landscape and then assessed the implications of altering management policy on ecological and social outcomes (through stocking rate changes at the lake and landscape scales). We did not simulate feedbacks between management policy and outcomes of these policy modifications. This may not be a substantial limitation however since feedbacks involving management policy are likely to be much slower than those related to ecological and angler behaviors (Ward et al. 2016; Arlinghaus et al. 2017). 
At the landscape scale, we treated features as a static framework of fishing opportunities and angler demand. In particular, the spatial distribution of climate, human abundance in cities/towns/rural, and transportation network provides the linkages from all angler locations to all lakes on the landscape were held constant. The S-SES model could be adapted however to evaluate the implications of changing human population growth, climate, fish production, and transportation patterns across the landscape.

The S-SES outcomes presented here are the net result of the dynamic processes among fish populations and a heterogeneous angler population across the ecological, angler and management landscape. The predictions from the S-SES do a reasonable job of characterizing the effort patterns across the landscape as assessed from an independent data set (i.e. mean predictions across many systems differ little). A priority for subsequent analyses is to characterize mechanisms behind the larger positive and negative residuals.

Ecological processes are a key determinant of the landscape patterns in fish populations and angler effort. Density- and climate-dependent processes result in within lake trade-offs between fish density and body size (Ward et al. 2017). Density, in this case, is a function of stocking and harvest rates; natural mortality rate and size-at-age is a function of density and climate. Altering stocking rates results in a complex set of outcomes across the landscape. In some situations, increasing stocking rates had the net effect of attracting more anglers implying that the manipulation increased local productivity that can be harvested by additional anglers. These lakes should be those that were originally stocked at rates whereby the net effect of an increase was to provide increased harvest opportunities, attracting anglers. The opposite situation was also encountered whereby increased stocking repelled anglers, suggesting that the densities were such that the ecological process of density-dependent growth reduced fish size to the point where 
the angling community assessed the fishing opportunity as less attractive, and anglers chose to fish elsewhere. These outcomes were therefore a function of the growth and survival of altered fish populations and effort and harvest behavior by the heterogeneous angler population. We observed a similar dynamic experimentally where we identified an empirical optimum stocking density, which maximized total fishing effort (Mee et al. 2016). Interestingly, when this experiment was replicated across regions, optima were found in both regions, but at very different stocking densities. The region with the higher human density had a much higher optimum stocking density due to higher total harvest mortality, than did a lower population density region. This result further supports the inference that the harvest dynamic works through a combination of density-dependent fish growth, harvest mortality and angler behavior driven by trade-offs between preferences for fish size and catch per unit effort (Parkinson et al. 2004; Wilson et al. 2016). Our landscape scale model outcomes, based on behavioral interactions between fish populations and angler communities, corroborate these experimental observations (Mee et al. 2016).

Spatial patterns in fishing effort are the outcome, as measured by utility, of the effort-fishing quality dynamic, plus several human features of the landscape. The spatial distribution of human settlements and the transportation network provides the template for this dynamic to unfold (Carpenter and Brock 2004; Hunt et al. 2011). But, there is much more richness to the network as participation rates in the fishery differ substantially across the landscape, with clear contrasts among large cities and small-towns. In the BRITISH COLUMBIArainbow trout fishery, we observed participation rates varying from $3.7 \%$ in the primarily urban Lower Mainland region to the northern, least urbanized region at $17.1 \%$ participation rate which is consistent with other landscape fisheries (Hunt et al. 2017). Although researchers often indict the process of 
746 urbanization and the disconnect of urban residents from nature as critical factors for reduced 747 fishing participation (Arlinghaus et al. 2015; Hunt et al. 2017), an alternate explanation is that 748 urban residents lack access to high quality fishing opportunities within reasonable travel time, 749 due to historical overfishing. This phenomenon has been described as producing low-quality 750 fishing shadows around large cities, dissipating with distance, because of high urban effort, 751 overfishing and collapse (Post et al. 2002; 2008; 2012; Post 2013). It is hard to disentangle these 752 competing hypotheses given snapshot observations, but we have experiments underway 753 involving enhanced fishing in or near cities to assess the propensity of urbanites to fish if local 754 opportunities are made available through stocking. heterogeneous across the landscape than considered in previous assessments of this fishery (Post et al. 2002; Post et al. 2008; Post and Parkinson 2012). They presumed that most of the fishing effort emanated from the Lower Mainland-Vancouver area which does contain by far the highest human density. But, it appears that substantial fishing effort also emanates from smaller communities throughout the interior of British Columbia, which although are much smaller centres, have higher participation rates. There is still an apparent south to north cline in effort and fishing quality, but is less distinct than considered earlier due to the spatially diffuse nature of angler's origin across the landscape.

Substantial heterogeneity in behavior exists within the population of anglers who use this fishery. Four groups were identified with varying responses to the characteristics of the individual lake fisheries. This segmentation of angler types is common in many recreational fisheries (e.g., Dorow et al. 2009; Beville et al. 2012; Carlin et al. 2012). Importantly, predictions of fishery outcomes in response to management initiatives are sensitive to angler behavioral 
heterogeneity in their responses to variation in catch and non-catch in attributes (Johnston et al. 2010; 2013; Fenichel et al. 2013). And, harvest dynamics are directly determined by the combination of angler behavior and fish population compensatory processes of densitydependent growth and size-dependent natural and fishing mortality (Lester et al. 2014). Therefore, assessing alternate management policies aimed at optimizing outcomes requires the inclusion of these dynamics. Yet mechanistic modelling approaches to fish-angler dynamics that incorporate both angler heterogeneity and realistic fish population structure are rare (Fenichel et al. 2013; Arlinghaus et al. 2017). Our simulations of management interventions involving stocking rates and harvest regulations revealed angler effort responses that varied substantially among angler groups and spatially. We would not have captured this heterogeneity in response to management policy changes if we modelled only the average angler.

While models such as S-SES may provide strategic benefits, their development is relatively costly. A large selection of data and models are required such as choice models to characterize angler preference (Dabrowska et al. 2017), biological models to characterize growth, a complete account of management measures for all lakes, lake-specific information such as productivity and size, and geographic information systems for characterizing landscape features such as size of population centres, distances among lakes and population centres, and access to lakes.

\section{Depending on the landscape configuration, the S-SES approach can also be computationally} intensive. The cost-efficacy analysis (Figure 10) required the calculation of 584 simulated landscapes which took 10 minutes on a contemporary workstation. Because the number of calculations required is the product of the number of population centres, angling classes and lakes, a larger landscape model with double of each of these dimensions entails 32 times more calculations, which may prevent real-time exploration of the model in a management workshop. 
There are several other limitations of the current S-SES approach that should be addressed by future model development. Extensive verification of S-SES is vital and should go beyond fitting the model to independently-estimated effort observations as we did. For example, S-SES predictions of effort changes from stocking experiments could be compared with observed effort changes where data is available. In our analyses, various simulations were undertaken in which stocking levels were altered arbitrarily and some of these stocking options may not be possible given fish hatchery production constraints. Further versions of the model could aim to integrate hatchery production and cost models to ensure realistic management options are evaluated. model. This model does not include the importance of contextual factors such as proximity of an angler to lakes outside of the modelled system. Consequently, the predictions from the model can overstate effort in lakes near the boundary of the study area. Future applications could consider alternate models that: (i) include important contextual factors in angler decision making by using information from stated and actual (revealed) choices by anglers (MacNair and Desvousges 2007); (ii) better connect fishing participation, effort, and site choices by anglers within more realistic time and budgetary constraints (e.g., Abbott and Fenichel 2013); and (iii) better understand how angler impacts on resources are influenced by gear and equipment selectivity.

The model also does not account for changes in license sales $(n)$ and in this regard, may

811 (Mee et al. 2016), future analyses could estimate limits on annual participation rate by angler 812 class to better characterize effort response. In parallel to these stocking density experiments the 813 research team has also completed a series of experiments in which angling regulations were 814 altered with controls and fishing effort monitored providing additional potential to test landscape 
815 scale prediction of this model. Additionally, historical license sales data may be investigated to 816 attempt to relate predicted angling quality to a prediction of license sales (see Hunt et al. 2017

817 for such an application). Note that even if responsiveness was inaccurate, the S-SES model may 818 still provide information regarding management priorities. For example, the patterns in the cost819 efficacy maps of Figure 10 are largely unaffected by alternative assumptions regarding the 820 maximum annual participation rate of angler classes.

821 Future research on the dynamics of social-ecological recreational fishery systems could take 822 three productive directions. First, enhancement of the framework that we developed for 823 application to naturally recruiting fisheries would be a useful advance (Arlinghaus et al. 2017).

824 This involves substantial complication of the ecological sub-model in which mean recruitment, 825 and inter-annual variability in recruitment, drives lake-scale fish production. Recruitment (as 826 stocking) in our model was a management policy rather than an ecological process. In addition, 827 this enhancement could include depensatory processes (Ward et al. 2013a; Perälä and Kuparinen 828 2017) and provide a more realistic assessment of the potential for overfishing and collapse with 829 important management and conservation implications for wild-stock fisheries. A second, and 830 very useful research direction, would be to subset the processes within the spatial SES to test 831 hypotheses that result in the emergent properties of the system. For example, questions related to 832 the importance of the spatial distribution of angler communities, lakes and transportation 833 networks could be assessed experimentally. Such an approach, could help to generalize the 834 patterns that emerge from dynamic SES interactions and could enhance our understanding in 835 ways that are not possible with an empirically derived SES, as in our analyses. And third, 836 development of a stochastic version of the model that incorporates variability of the key 837 behavioral processes would be useful in assessment of the robustness of alternate management 
838 policy options under uncertainty, and the value of additional information in optimizing outcomes 839 of the S-SES.

840

\section{ACKNOWLEDGEMENTS}

842 We acknowledge the Natural Science and Engineering Research Council of Canada for funding a 843 Collaborative Research and Development Grant in partnership with the Freshwater Fisheries 844 Society of British Columbia and the Habitat Conservation Trust Foundation. We also 845 acknowledge fishery biologists with the Freshwater Fisheries Society of British Columbia and 846 the British ColumbiaMinistry of Forest, Lands, Natural Resource Operations and Rural 847 Development who were instrumental in the planning and development of this landscape scale 848 adaptive and experimental management program, in particular, Vicki Lewis, Cory Williamson, 849 Steve Maricle and Lee Williston. Thanks also to Natasha Carr and Dan Taillon for their helpful 850 comments on an earlier version of this paper. 


\section{REFERENCES}

Aas, O., Haider, W., Hunt, L.M. 2000. Angler responses to potential harvest regulations in a Norwegian sport fishery: a conjoint-based choice modeling approach. North American Journal of Fisheries Management. 20:940-950.

Abbott, J.K., Fenichel. E.P. 2013. Anticipating adaptation: a mechanistic approach for linking policy and stock status to recreational angler behavior. Canadian Journal of Fisheries and Aquatic Sciences. 70: 1190-1208.

Allan, J.G., Abell, R.,Hogan, Z., Revenga, C., Taylor, B. W., Welcomme, R., Winemiller, K.W. 2005. Overfishing of Inland Waters. Bioscience 55:1041-1051.

Arlinghaus, R., Mehner, T. 2005. Determinants of management preferences of recreational anglers in Germany: Habitat management versus fish stocking. Limnologica - Ecology and Management of Inland Waters. 35: 2-17. https://doi.org/10.1016/j.limno.2004.10.001.

Arlinghaus, R., Alos, J., Beardmore, B., Daedlow, K., Dorow, M., Fujitani, M., Huhn, D., Haider, W., Hunt, L., Johnson, B., Johnston, F., Matsumura, T.S., Monk, C., Page T., Post, J.R., Riepe, C., Ward, H., Wolter, C. 2017. Understanding and managing freshwater recreational fisheries as complex adaptive social-ecological systems. Reviews in Fisheries Science and Aquaculture 25:1-41.

Arlinghaus, R., Beardmore, B., Riepe, C., Meyerhoff, J., Pagel, T. 2014. Species-specific preferences of German recreational anglers for freshwater fishing experiences, with emphasis on the intrinsic utilities of fish stocking and wild fishes: utility of stocking to freshwater anglers. Journal of Fish Biology. 85(6), 1843-1867. https://doi.org/10.1111/jfb.12546

Arlinghaus, R., Tillner, R., Bork, M. 2015. Explaining participation rates in recreational fishing across industrialised countries. Fisheries Management and Ecology 22: 45-55. 
Askey, P.J., Parkinson, E.A., Post, J.R. 2013. Linking fish and angler dynamics to assess stocking strategies for hatchery-dependent, open-access recreational fisheries. North American Journal of Fisheries Management. 33(3): 557-568.

Bailey, M., Sumaila, U.R. 2012. Freshwater Angling and the British Columbia Economy. Report prepared for the Freshwater Fisheries Society of B.C. 54 pp.

Beardmore, B., Dorow, M., Haider, W., Arlinghaus, R. 2011. The elasticity of fishing effort response and harvest outcomes to altered regulatory policies in eel (Anguilla anguilla) recreational angling. Fisheries Research, 110(1), 136-148.

Ben-Akiva, M. E., Lerman, S. R. 1985. Discrete Choice Analysis: Theory and Application to Travel Demand, MIT Press, Cambridge, Ma.

Beville, S.T., Kerr, G.N., Hughey, K.F.D. 2012. Valuing impacts of the invasive alga Didymosphenia geminata on recreational angling. Ecological Economics 82: 1-10.

Carlin, C., Schroeder, S.A., Fulton, D.C. 2012. Site Choice among Minnesota Walleye Anglers: The Influence of Resource Conditions, Regulations and Catch Orientation on Lake Preference. North American Journal of Fisheries Management 32: 299-312.

Carpenter, S.R., Brock, W.A. 2004. Spatial complexity, resilience, and policy diversity: fishing on lake-rich landscapes. Ecology and Society 9, 8. [online] Available at: http://www.ecologyandsociety.org/vol9/iss1/art8/.

Carson, R.T., Hanneman, W.M., Wegge, T.C. 2009. A nested logit model of recreational fishing demand in Alaska. Marine Resource Economics, 24, 101-129.

Cash, D.W., Adger, N.W., Berks, F., Garden, P, Lebel, L., Olsson, P., Prichard, L., Young, O. 2018. Scale and Cross-Scale Dynamics: Governance and Information in a Multilevel World. Ecology and Society. 11(2): 8. 
898

899

900

901

902

903

904

905

906

907

908

909

910

911

912

913

914

915

916

917

918

Cenek, M., Franklin, M. 2017. An adaptable agent-based model for guiding multi-species Pacific Salmon fisheries management within a SES framework. Ecological Modelling. Volume 360: 132-149, https://doi.org/10.1016/j.ecolmodel.2017.06.024.

Cox, S. Walters, C.J., Post, J.R. 2003. A model-based evaluation of active management of recreational fishing effort. N. Am. J. Fish. Manage. 23:1294-1302.

Cox, S., Walters, C. 2002. Modeling exploitation in recreational fisheries and implications for effort management on British Columbia rainbow trout lakes. N. Am. J. Fish. Manage. 22: 21-

Dabrowksa, K., Hunt, L. M., Haider, W. 2017. Understanding How Angler Characteristics and Context Influence Angler Preferences for Fishing Sites. North American Journal of Fisheries Management, 37(6), 1350-1361. https://doi.org/10.1080/02755947.2017.1383325

Dabrowska, K., Haider, W., Hunt, L. 2014. Examining the impact of fisheries resources and quality on license sales. Journal of Outdoor Recreation and Tourism. 5:6:58-67.

DFO. 2010. Survey of Recreational Fishing in Canada 2010. Department of Fisheries and Oceans Canada. Available at: http://www.dfompo.gc.ca/stats/rec/can/2010/RECFISH2010_ENG.pdf [accessed 20/5/2015]

Drake, D. A. R., Mandrak, N. E. 2010. Least-cost transportation networks predict spatial interaction of invasion vectors. Ecological Applications. 20: 2286-2299.

Dorow, M., Arlinghaus, R. 2012. The Relationship between Personal Commitment to Angling and the Opinions and Attitudes of German Anglers towards the Conservation and Management of the European Eel, Anguilla anguilla. North American Journal of Fisheries Management 32: 466-479. https://doi.org/10.1080/02755947.2012.680006 
Fenichel, E. P., Abbott, J. K., Huang, B., 2013. Modelling angler behaviour as part of the management system: synthesizing a multi-disciplinary literature. Fish and Fisheries. 14, 137157.

Folke, C., Carpenter, S.R., Walker, B., Scheffer, M., Chapin, T., Rockström, J. 2010. Resilience thinking: integrating resilience, adaptability and transformability. Ecology and Society 15(4): 20. [online] URL: http://www.ecologyandsociety.org/vol15/iss4/art20/

Fulton, E. A., Smith, A. D. M., Smith, D. C., van Putten I. E. 2011. Human behaviour: the key source of uncertainty in fisheries management. Fish and Fisheries. 12:2-17.

Hanski, I. 1999. Metapopulation Eccology. Oxford University Press. pp 328.

Hunt, L. M. 2005. Recreational fishing site choice models: insights and future opportunities. Human Dimensions of Wildlife 10, 153-172.

Hunt L. M., Arlinghaus R., Lester N., Kushneriuk R. 2011. The effects of regional fishing effort, angler behaviour, and harvesting efficiency on landscape patterns of overfishing. Ecological Applications 21, 2555-2575.

Hunt L. M., Bannister, A. E., Drake, D. A. R., Fera, S. A., Johnson, T. B. 2017. Do fish drive recreational fishing license sales? North American Journal of Fisheries Management 37: 122132.

Hunt L. M., Kushneriuk R., Lester N. 2007. Linking agent-based and choice models to study outdoor recreation behaviours: a case study of the Landscape Fisheries Model in northern Ontario, Canada. Forest Snow Landscape Research 81, 163-174.

Johnston, F.D., Arlinghaus, R., Dieckmann, U. 2010. Diversity and complexity of angler behaviour drive socially optimal input and output regulations in a bioeconomic recreational fisheries model. Canadian Journal of Fisheries and Aquatic Sciences 67:1507-1531. 
942

943

944

945

946

947

948

949

950

951

952

953

954

955

956

957

958

959

960

961

962

963

964

Johnston, F.D., Arlinghaus, R., Dieckmann, U. 2013. Fish life history, angler behaviour and optimal management of recreational fisheries. Fish and Fisheries 14: 554-579.

Kennedy, M., Gray, R.D. 1993. Can ecological theory predict the distribution of foraging animals? A critical analysis of experiments on the ideal free distribution. Oikos 68:158-166.

Lester, N.P., Shuter, B.J., Venturelli, P., Nadeau, D. 2014. Life-history plasticity and sustainable exploitation: a theory of growth compensation applied to walleye management. Ecol. App. 24(1): $38-54$.

Lester, N.P., Shuter, B.J., Abrams, P.A. 2004. Interpreting the von Bertalanffy model of somatic growth in fishes: the cost of reproduction. Proc. Soc. Lon. B. 271:1625-1631.

Levin, S., Xepapadeas, T., Crépin, A., Norberg, J., De Zeeuw, A., Folke, C., Hughes, T., Arrow, K., Barrett, S., Daily, G., Ehrlich, P., Kautsky, N., Maler, K-G., Polasky, S., Troell, M., Vincent, J.R., Walker, B. 2013. Social-ecological systems as complex adaptive systems: Modeling and policy implications. Environment and Development Economics, 18(2), 111132. doi: $10.1017 / \mathrm{S} 1355770 \mathrm{X} 12000460$

Liu, J., Dietz, T., Carpenter, S., Alberti, M., Folke, C., Moran, E., Pell, A., Deadman, P., Kratz, T., Lubchenco, J., Ostrom, E., Ouyang, Z., Provencher, W., Redman, C., Schneider, S., Taylor, W. 2007. Complexity of Coupled Human and Natural Systems. Science. 317. 1513-6. 10.1126/science.1144004.

MacNair, D., Desvousges, W.H. 2007. The economics of fish consumption advisories: insights from revealed and stated preference data. Land Economics 83: 600-616.

McGinnis, M. D., Ostrom. E. 2014. Social-ecological system framework: initial changes and continuing challenges. Ecology and Society, 19(2): 30. http://dx.doi.org/10.5751/ES-06387$\underline{190230}$ 
965 Mee, J. A., Post, J. R., Ward, H., Wilson, K.L., Newton, E., Cantin, A. 2016. Interaction of 966 ecological and angler processes: experimental stocking in an open access, spatially structured 967 fishery. Ecological Applications 26:1693-1707.

968 MOE. 2007. Freshwater Fisheries Program Plan. Province of British Columbia, Ministry of 969 Environment. Available at: http://www.env.gov.bc.ca/esd/documents/ff program plan.pdf $970 \quad$ [accessed 20/5/2015]

971

972

973

974

975

976

977

978

979

980

981

982

983

984

985

986

987

Muirhead, J.R., MacIsaac, H.J. 2011. Evaluation of stochastic gravity model selection for use in estimating non-indigenous species dispersal and establishment. Biological Invasions 13: $2445-2458$

Murtagh, F., Legendre, P. 2014. Ward's hierarchical agglomerative clustering method: which algorithms implement Ward's criterion? Journal of Classification 31:274-295.

Neuheimer, A.B., Taggart, C.T. 2007. The growing degree-day and fish size-at-age: the overlooked metric. Can. J. Fish. Aqua. Sci. 64:375-385. https://doi.org/10.1139/f07-003

Ostrom, E. 2009. A general framework for analysing sustainability of social-ecological systems. Science 319:419-422.

Parkinson, E. A., Post, J. R., Cox, S. P. 2004. Linking the dynamics of harvest effort to recruitment dynamics in a multistock, spatially structured fishery. Can. J. Fish. Aquat. Sci. 61:

$$
1658-1670 .
$$

Perälä, T., Kuparinen, A. 2017. Detection of Allee effects in marine fishes: analytical biases generated by data availability and model selection. Proceedings of the Royal Society B 284.

Post, J. R. 2013. Resilient recreational fisheries or prone to collapse? A decade of research on the science and management of recreational fisheries. Fisheries Management and Ecology 20:99110. 
Post, J. R. Parkinson, E.A. 2012. Temporal and spatial patterns of angler effort across lake districts and policy options to sustain recreational fisheries. Canadian Journal of Fisheries and Aquatic Sciences 69:321-329.

Post, J. R., Sullivan, M., Cox, S., Lester, N.P., Walters, C. J., Parkinson, E. A., Paul, A. J., Jackson, L., Shuter, B.J. 2002. Canada's recreational fisheries: the invisible collapse? Fisheries 27(1):6-17.

Post, J. R., Persson, L., Parkinson, E.A. van Kooten, T. 2008. Angler numerical response across landscapes and the collapse of freshwater fisheries. Ecological Applications 18:1038-1049.

Provencher, B., Bishop, R.C. 2004. Does Accounting for Preference Heterogeneity Improve the Forecasting of a Random Utility Model? A Case Study. Journal of Environmental Economics and Management 48 (1): 793-810.

R Core Team. 2017. R: A language and Environment for Statistical Computing. R Foundation for Statistical Computing, Vienna, Austria. Url: http://www.R-project.org.

Radomski, P.J., Grant, G.C., Jacobson, P.C., Cook, M.F. 2001. Visions for recreational fishing regulations. Fisheries. 26(5): 7-18.

Sanchirico, J.N., Wilen, J.E. 1999. Bioeconomics of spatial exploitation in a patchy environment. Journal of Environmental Economics and Management. 37:129-150.

Sanchirico, J.N., Wilen, J.E. 2005. Optimal spatial management of renewal resources: matching policy scope to ecosystem scale. Journal of Environmental Economics and Management. 50:23-46.

Synes, N.W., Brown, C., Watts, K., White, S.M., Gilbert, M.A., Travis, J.M.J. 2016. Emerging Opportunities for Landscape Ecological Modelling. Current Landscape Ecology Reports. 1(4): 146-167. 
1011 Swait, J. 1994. A structural equation model of latent segmentation and product choice for cross1012 sectional revealed preference choice data, Journal of Retail and Consumer Services, 1(2), 77101389.

1014 Walters, C.J., Post, J.R. 1993. Density-dependent growth and competitive asymmetries in size1015 structured fish populations: a theoretical model and recommendations for field experiments. 1016 Trans. Am. Fish. Soc. 122:34-45.

1017 Wang, T., Spittlehouse, D. L., Hamann, A. 2015. A program to general climate normal, annual, 1018 seasonal and monthly data for historical and future periods in British Columbia. University of 1019 British Columbia, Vancouver.

1020 Ward, H.G.M, Askey, P.J., Post, J.R. 2013a. A mechanism understanding of hyperstability in 1021 catch per unit effort and density-dependent catchability in a multistock recreational fishery. 1022 Can. J. Fish. Aqua. Sci. 70: 1542-1550.

1023 Ward, H.G.M., Quinn, M.S., Post, J.R. 2013b. Angler characteristics and management 1024 implications in a large multi-stock spatially structured recreational fishery. North American 1025 Journal of Fisheries Management. 33:576-584.

1026 Ward, H.G.M., Allen, M.S., Camp, E., Cole, N., Hunt, L.M., Matthias, B., Post, J.R., Wilson, K., 1027 Arlinghaus, R. 2016. Understanding and managing social-ecological feedbacks in spatially1028 structured recreational fisheries: the overlooked behavioral dimension. Fisheries 41:524-535. 1029 Wilson, K.L., Cantin, A. Ward, H., Newton, E.R., Mee, J.A., Varkey, D., Parkinson, E.A., Post, 1030 J.R. 2016. Supply-demand equilibria and the size-number tradeoff in spatially structured 1031 recreational fisheries. Ecological Applications 26: 1086-1097.

1032 Wu, J., Luocks, O.L. 1995. From Balance of Nature to Hierarchical Patch Dynamics: A 1033 Paradigm Shift in Ecology. Quarterly Review of Biology. 70. 439-466. doi: 10.1086/419172. 
Table 1. Equation parameters, variables and indexes in order of their appearance in the manuscript. 'Eqn' refers to the first equation where the symbol was used. Some units are abbreviated: day (d), year (y), hectare (ha).

\begin{tabular}{|c|c|c|c|}
\hline $\begin{array}{l}\text { Parameter / } \\
\text { variable }\end{array}$ & Description & Units & Eqn. \\
\hline$E$ & Angler effort & $\mathrm{d}$ & 1 \\
\hline$m$ & Maximum effort for a class of anglers & $\mathrm{d}$ & 1 \\
\hline$G$ & Weight of a lake & & 1 \\
\hline$\tau$ & Weight of not angling modelled lakes & & 1 \\
\hline$n$ & Number of licenses sold & Licenses & 1 \\
\hline $\bar{E}$ & Mean effort of an angler class & $\mathrm{d} \mathrm{y}^{-1}$ & 1 \\
\hline$d$ & Lake distance (travel distance) & $\mathrm{km}$ & 3 \\
\hline$C$ & Expected catch rate & Fish $\mathrm{ha}^{-1} \mathrm{~d}^{-1}$ & 3 \\
\hline$S$ & Expected size of fish caught & $\mathrm{mm}$ & 3 \\
\hline$X$ & Angler crowding & Anglers ha ${ }^{-1}$ & 3 \\
\hline$H$ & A set of categorical lake attributes & & 3 \\
\hline$W$ & An accessibility score & & 3 \\
\hline$D$ & Fish population density & $10^{-6} \mathrm{~mm}^{2} \mathrm{ha}^{-1}$ & 4 \\
\hline$N$ & Predicted number of fish & Fish & 4 \\
\hline$L$ & Predicted length of fish & $\mathrm{mm}$ & 4 \\
\hline$v$ & Lake surface area & ha & 4 \\
\hline$\widehat{G}$ & Growing degree days & $\mathrm{d} \mathrm{y}^{-1}$ & 5 \\
\hline$Q$ & Thermal age & $1000 \mathrm{~d}$ & 5 \\
\hline$L^{\infty}$ & Maximum length & $\mathrm{mm}$ & 6 \\
\hline$K$ & Slope of growth at the origin & $\mathrm{mm} \mathrm{y}^{-1}$ & 6 \\
\hline$t_{0}$ & Theoretical age at length zero & $\mathrm{y}$ & 6 \\
\hline$Y$ & Thermal age at maturation & $1000 \mathrm{~d}$ & 6 \\
\hline$h$ & Density-dependent juvenile growth & $\mathrm{mm} \mathrm{y}^{-1}$ & 6 \\
\hline$L_{s}$ & Length at the time of stocking & $\mathrm{mm}$ & 6 \\
\hline$\gamma$ & Slope parameter for calculation of $Y$ from $h$ & & 7 \\
\hline$\delta$ & Exponent parameter for calculation of $Y$ from $h$ & & 7 \\
\hline$\Delta$ & Slope parameter for calculation of $h$ from $D, G$ and $L_{s}$ & & 8 \\
\hline$\beta$ & Exponent parameter for calculation of $h$ from $D, G$ and $L_{s}$ & & 8 \\
\hline$\alpha$ & Exponent parameter for calculation of $h$ from $D, G$ and $L_{s}$ & & 8 \\
\hline$g$ & Proportion of surplus energy allocated to reproduction & & 9 \\
\hline$R$ & Total fraction of fish removed by anglers & Fish $^{-1}$ & 10 \\
\hline$q$ & Catchability & ha $\mathrm{d}^{-1}$ & 12 \\
\hline$s$ & Selectivity (fraction of maximum harvest rate at age) & & 12 \\
\hline$\Phi$ & Fraction of trips exceeding the bag limit & $y^{-1}$ & 13 \\
\hline$B$ & Daily bag limit & Fish $d^{-1}$ & 13 \\
\hline$F$ & Instantaneous annual fishing mortality rate & $\mathrm{y}^{-1}$ & 14 \\
\hline$V$ & Voluntary release rate & $\mathrm{y}^{-1}$ & 14 \\
\hline$\psi$ & Post-release mortality rate & $\mathrm{y}^{-1}$ & 14 \\
\hline$Z$ & Total instantaneous annual mortality rate & $\mathrm{y}^{-1}$ & 15 \\
\hline$M$ & Natural mortality rate at age & $\mathrm{y}^{-1}$ & 15 \\
\hline
\end{tabular}


1037 Table 1 cont.

\begin{tabular}{clll}
\hline $\begin{array}{c}\text { Parameter / } \\
\text { Variable }\end{array}$ & Description & Units & Eqn. \\
\hline$N^{0}$ & Stocking numbers & Fish & 16 \\
$\theta$ & Relaxation parameter for numerical effort calculation & & 20 \\
$E^{\text {trial }}$ & Proposed effort from numerical effort calculation & $\mathrm{d}$ & 20 \\
$\Omega$ & Dissimilarity matrix based on lake distances & $\mathrm{km}$ & 21 \\
$\kappa$ & Slope parameter controlling contribution of W to G & & 22 \\
gravel & Distance on gravel roads & $\mathrm{km}$ & 23 \\
$4 W D$ & Distance on roads suitable for all-terrain vehicles & $\mathrm{km}$ & 23 \\
foot & Distance by footpath & $\mathrm{km}$ & 23 \\
OBJ & Global objective minimized when fitting observed effort & & 24 \\
$E^{\text {obs }}$ & Observed angling effort & $\mathrm{d}$ & $\mathrm{d}$ \\
$E^{\text {pred }}$ & Model predicted angling effort & & 24 \\
& & Units & Eqn. \\
Index & Description & & 1 \\
\hline$A$ & Angler class & & 1 \\
$p$ & Population centre & & 1 \\
$l$ & Lake & $\mathrm{y}$ & 4 \\
$T$ & Stocking type (e.g. fry, catchable) & Fish d ${ }^{-1}$ & 4 \\
$a$ & Age of fish (integer) & & 13 \\
$j$ & A discrete catch rate of fish & & 20 \\
$i$ & Iteration of the numerical effort calculation & & \\
$\bar{p}$ & Population centre for pair-wise comparison & & \\
& & & \\
\hline & & & \\
\hline
\end{tabular}


1040 Table 2. Regional lake attributes. The number and names or regions are indicated with mean and 1041 standard deviation of attributes of lakes in the regions.

\begin{tabular}{|c|c|c|c|c|c|c|c|c|c|}
\hline \multirow[t]{2}{*}{ Region } & \multicolumn{2}{|c|}{$\begin{array}{c}\text { Lake area } \\
\text { (ha) }\end{array}$} & \multicolumn{2}{|c|}{$\begin{array}{c}\text { Growing } \\
\text { degree days }\end{array}$} & \multirow{2}{*}{$\begin{array}{c}\text { Total } \\
\text { lake-years } \\
\text { of data }\end{array}$} & \multicolumn{2}{|c|}{$\begin{array}{c}\text { Angler effort } \\
\text { density }\left(\mathrm{d} \mathrm{ha}^{-1}\right. \\
\left.\mathrm{yr}^{-1}\right)\end{array}$} & \multicolumn{2}{|c|}{$\begin{array}{l}\text { Stocking Rate } \\
\left(\text { fish ha } \mathbf{h a}^{-1}\right)\end{array}$} \\
\hline & Mean & St.Dev & Mean & St.Dev & & Mean & St.Dev & Mean & St.Dev \\
\hline Lower & & & & & & & & & \\
\hline Mainland & 113 & 359 & 1853 & 262 & 11 & NA & NA & 42 & 49 \\
\hline Thompson & 56 & 100 & 1168 & 268 & 415 & 47.2 & 34.0 & 125 & 103 \\
\hline Kootenay & 518 & 3625 & 1413 & 242 & 180 & 25.7 & 13.9 & 138 & 126 \\
\hline Cariboo & 206 & 407 & 1237 & 166 & 352 & 8.9 & 9.6 & 105 & 72 \\
\hline Skeena & 52 & 92 & 1226 & 188 & 0 & NA & NA & 68 & 46 \\
\hline Omineca & 162 & 397 & 1247 & 152 & 175 & 6.7 & 7.9 & 84 & 55 \\
\hline Okanagan & 34 & 58 & 1188 & 315 & 475 & 20.0 & 16.5 & 176 & 150 \\
\hline Peace & 52 & 60 & 1143 & 150 & 0 & NA & NA & 67 & 47 \\
\hline
\end{tabular}


1043 Table 3. The values assigned to parameters of the rainbow trout population dynamics model.

\begin{tabular}{|c|c|c|c|c|c|c|c|c|}
\hline Parameter & $\gamma$ & $\delta$ & $\Delta$ & $\beta$ & $\alpha$ & $g$ & $\boldsymbol{V}$ & $\Psi$ \\
\hline Value & 30.4 & 0.5698 & 207.7 & -0.1457 & 0.0099 & 0.2139 & 0.49 & 0.05 \\
\hline Age class & 0-1 & $1-2$ & $2-3$ & $3-4$ & $4-5$ & $5-6$ & & \\
\hline Natural mortality rate $M\left(\mathrm{y}^{-1}\right)$ & 0.5 & 0.025 & 0.025 & 0.7 & 0.8 & 0.8 & & \\
\hline Selectivity $s$ & 0 & 0.5 & 1 & 1 & 1 & 1 & & \\
\hline Stocking type & Fry & Yearling & Catchable & & & & & \\
\hline Age at release & $0-1$ & $1-2$ & $2-3$ & & & & & \\
\hline Length at stocking $R$ (mm) & 50 & 100 & 200 & & & & & \\
\hline Angler class & Generalists & Social & Enthusiasts & Occasional & & & & \\
\hline Catchability $q\left(\right.$ ha d $\left.^{-1}\right)$ & 0.0705 & 0.0687 & 0.0739 & 0.0348 & & & & \\
\hline 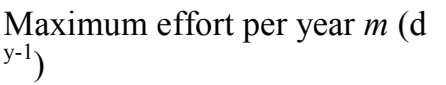 & 97 & 95 & 100 & 48 & & & & \\
\hline
\end{tabular}

1044 
1046 LIST OF FIGURES

1047 Figure 1. Map of the British Columbia recreational trout fishery. Solid points on the map

1048 represent 584 lakes that are stocked with at least 200 trout per year and are over 5 hectares in

1049 surface area. Black solid points are the 34 'training lakes' that were used to condition the

1050 landscape mode. A total of 24 human population centres were modelled. The labelled white

1051 points represent 8 of the 24 population centres that are large discrete towns or cities. The area of

1052 these points is proportional to the number of license sales by population centre.

1053 Figure 2. The social, ecological and management components of the S-SES model and their

1054 interactions.

1055 Figure 3. Continuous utility models (plotted lines) for four classes of angler in respect to (a)

1056 angler crowding, (b) expected catch rate, (c) travel distance to lake and (d) expected size of fish.

1057 Points represent the results of the choice experiment of Dabrowska et al. (2014).

1058 Figure 4. Estimated part-worth utility of categorical lake attributes by angler class, including

1059 gear restrictions, take limit (maximum number of fish that may be caught and harvested per day),

1060 lake size, motor restrictions and launching facilities.

1061 Figure 5. Numerical convergence to the ideal free distribution of effort given alternative values

1062 for the relaxation parameter $\theta$. The vertical grey line represents the iteration in which

1063 convergence has been achieved (all effort predictions are now within 0.1 day of the previous

1064 iteration).

1065 Figure 6. The fit of the model to observed effort, and the natural logarithm of effort, for the 1066 experimental lakes (black) and British Columbia-wide lakes (grey). The black line represents a 1067 best fit linear model through the observed and predicted data for the experimental lakes (with 1068 zero intercept). The dashed grey line represents a line of slope $1 . R^{2}$ statistics are provided for the 1069 experimental (black) and British Columbia-wide lakes (grey). 
1070 Figure 7. Local angling effort redistribution arising from doubling the number of stocked fish 1071 for three lakes across the landscape. Grey points on panel $\mathrm{c}$ represent lakes, black boxes 1072 correspond with the regions of panels $\mathrm{a}, \mathrm{b}$ and $\mathrm{d}$. The width of arrows is proportional to the 1073 amount of effort that was redistributed from local lakes.

1074 Figure 8. The model predicted catch rate and size of fish caught by anglers in each management 1075 region. The vertical dashed lines correspond to the mean value which is also given as a number 1076 in the top right-hand corner of each plot.

1077 Figure 9. Regional equity in landscape usage and utility. Panel a: the model predicted effort 1078 originating from various regions on all lakes (thousand days). Panel b: the mean part-worth 1079 utility of the highest 20 ranking lakes for each region and angler class. Note that in some regions 1080 there are no members of an angler class (for example there are no occasional anglers in Omineca 1081 Rural and Fort St John regions).

1082 Figure 10. Spatial pattern of cost/benefit from increased stocking. The map represents 584 1083 independent runs of the landscape model (one run for each lake). In each model run, stocking on 1084 a particular lake is increased by $10 \%$ and the cost/benefit of that manipulation is calculated as the 1085 total resulting landscape effort divided by the total cost of stocking. Black points represent 1086 occasions where the increased stocking led to higher effort per \$ stocking costs. White points 1087 represent occasions where the increases stocking led to lower effort per \$ stocking costs.

1088 Figure 11. Model predicted effort response to increased stocking of lakes nearer or further than $1089100 \mathrm{~km}$ from an urban centre. Panel a: the manipulated lakes. Panel b: effort response (\%) to 1090 increased stocking of lakes within $100 \mathrm{~km}$ of an urban centre. Panel c: effort response (\%) to 1091 increased stocking of lakes further than $100 \mathrm{~km}$ from an urban centre. 
1092 Figure 12. Changes in angling effort (\%) (panel b) over the landscape in response to increasing 1093 the number of trophy lakes (in this example lakes with a bag limit of 2 fish per day, panel a).

1094 


\section{Figure 1}

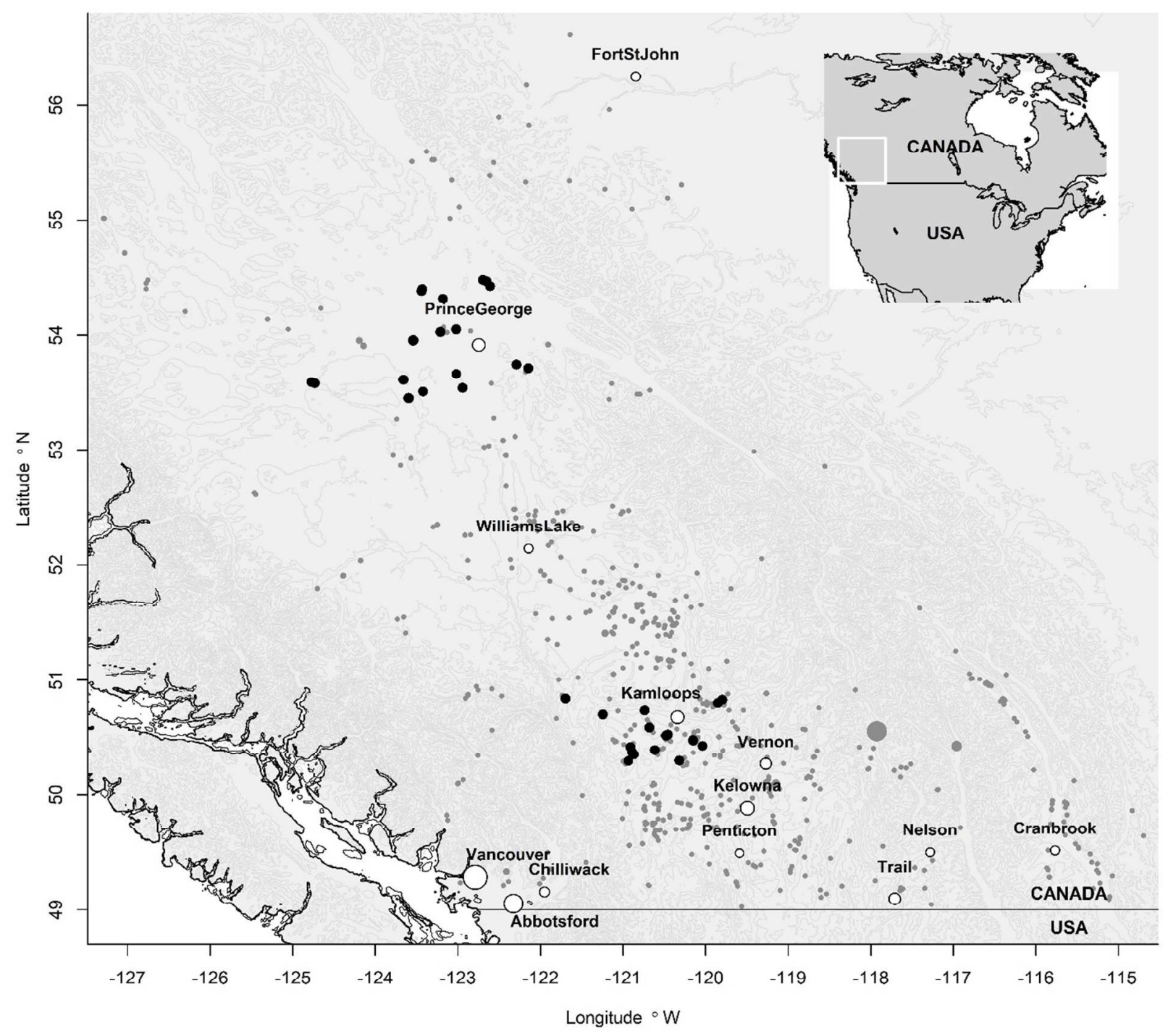

1096 
$1097 \quad$ Figure 2

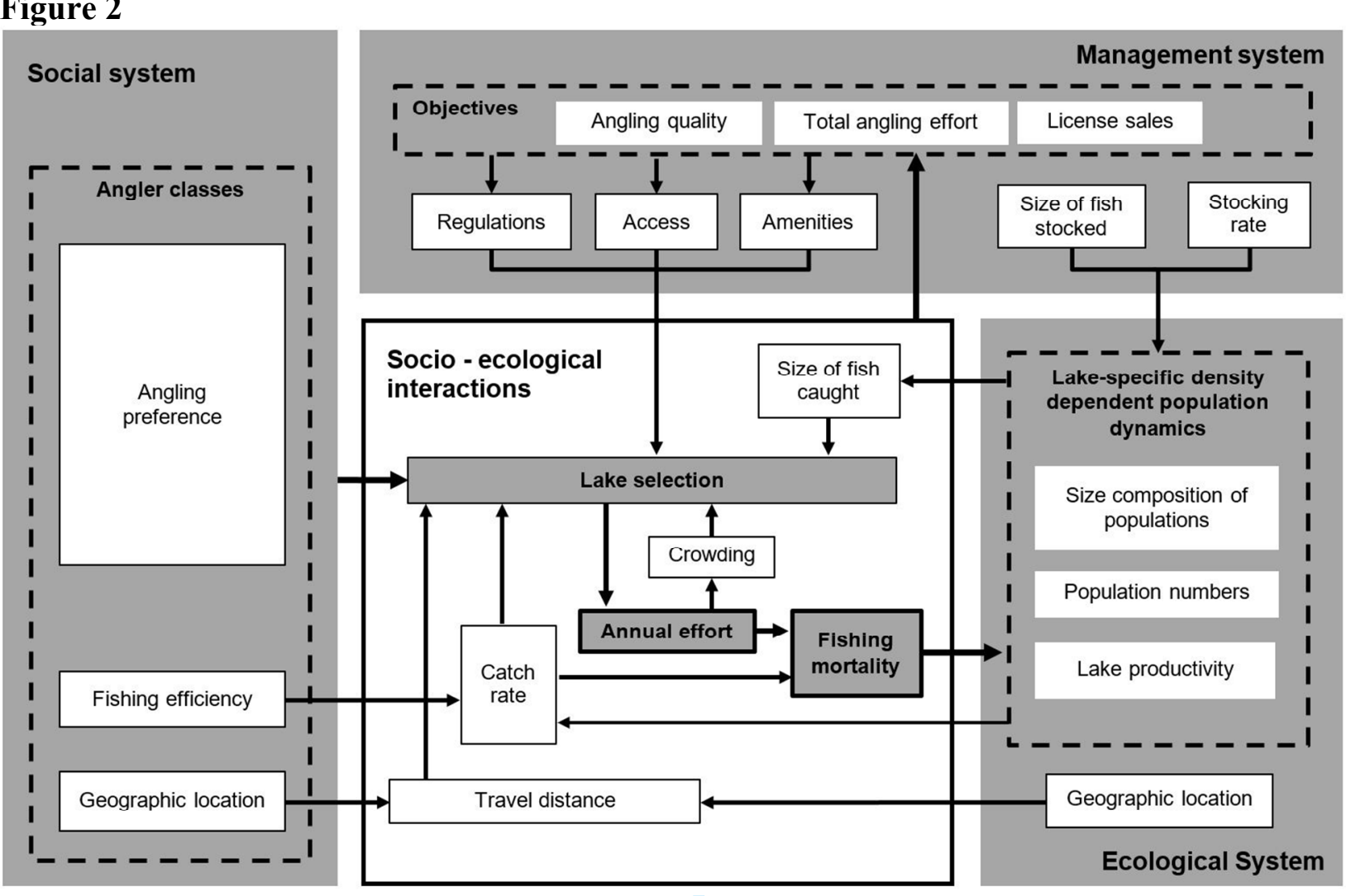


1099 Figure 3

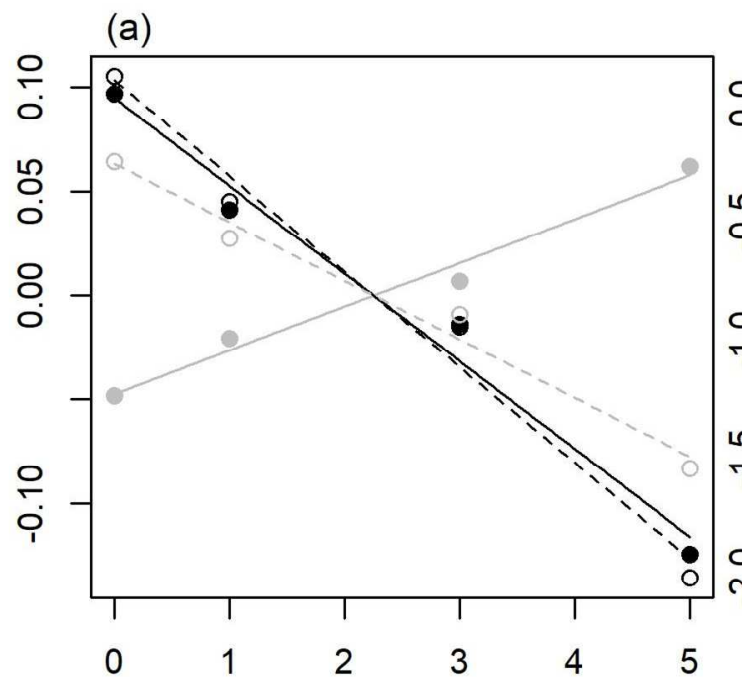

(b)
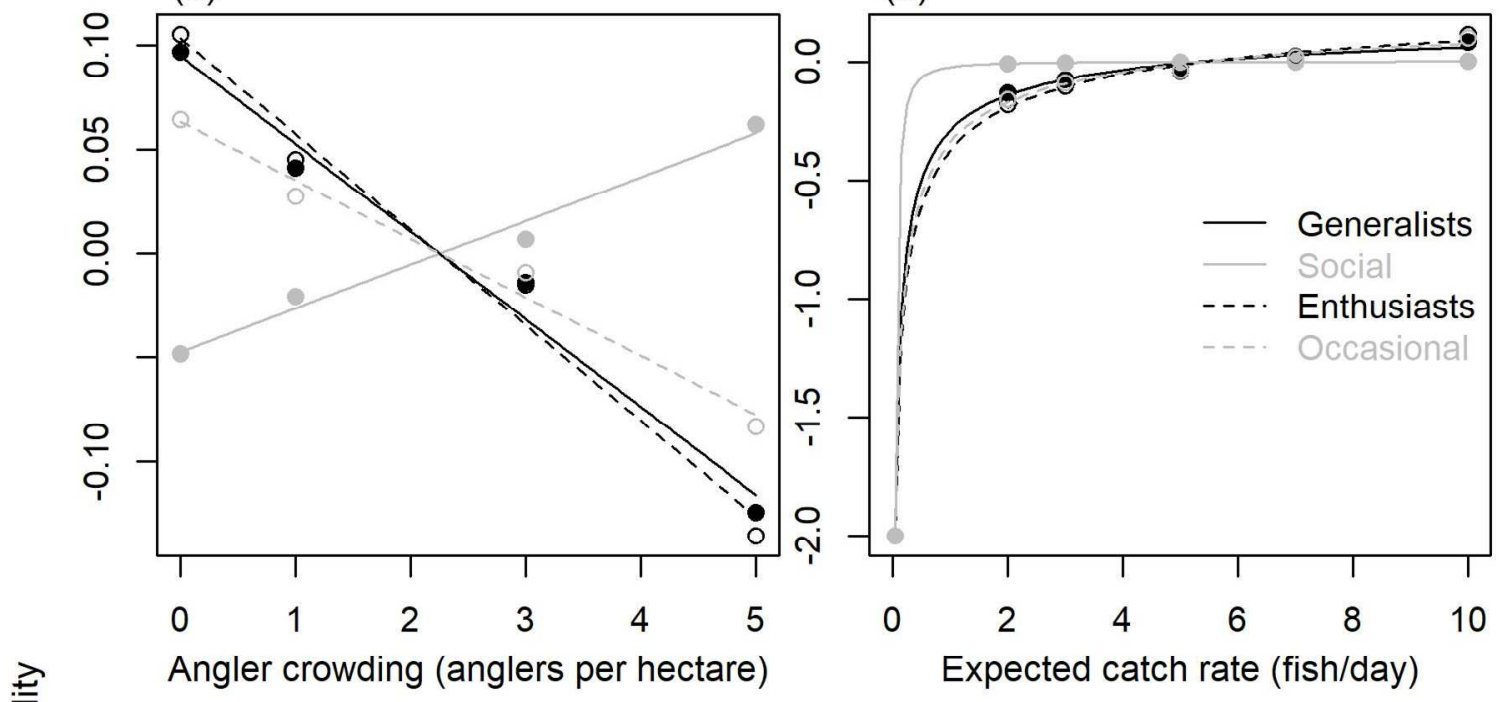

(d)
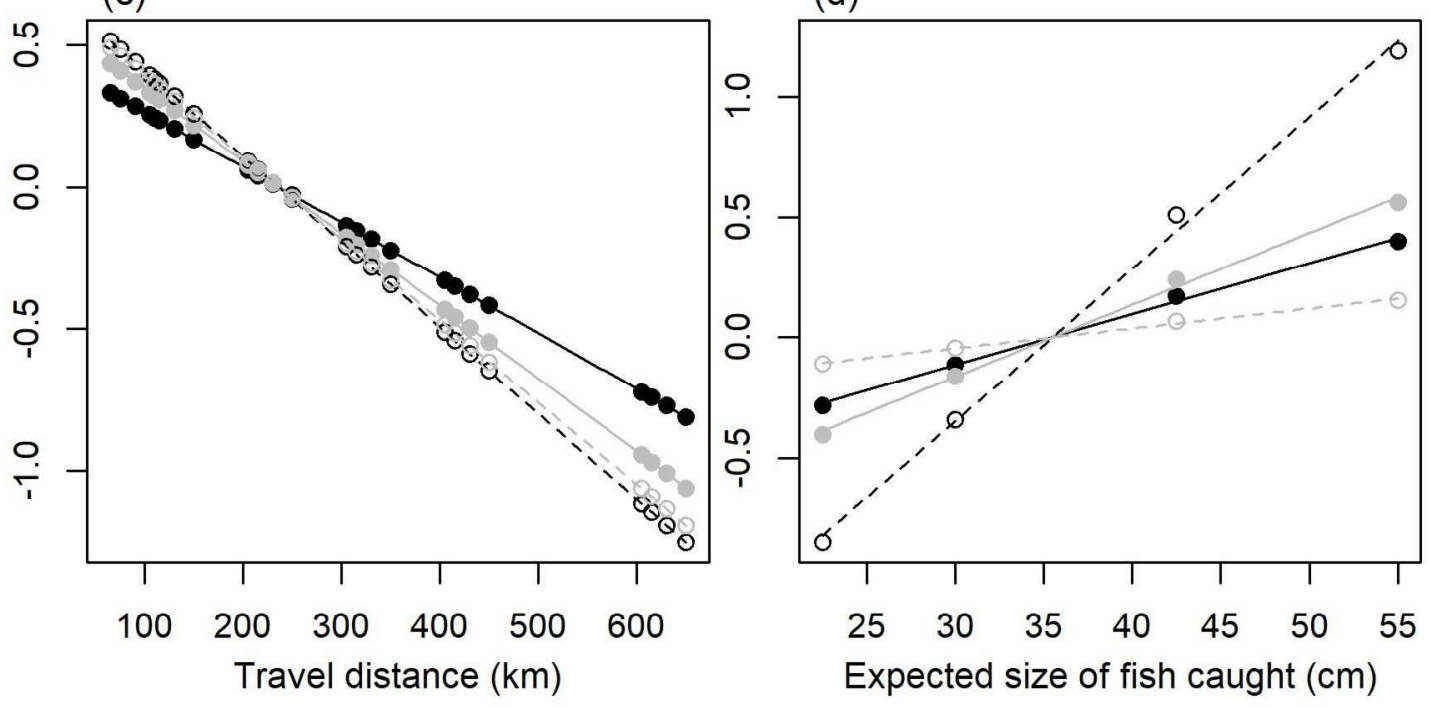

1100

1101 


\section{Figure 4}
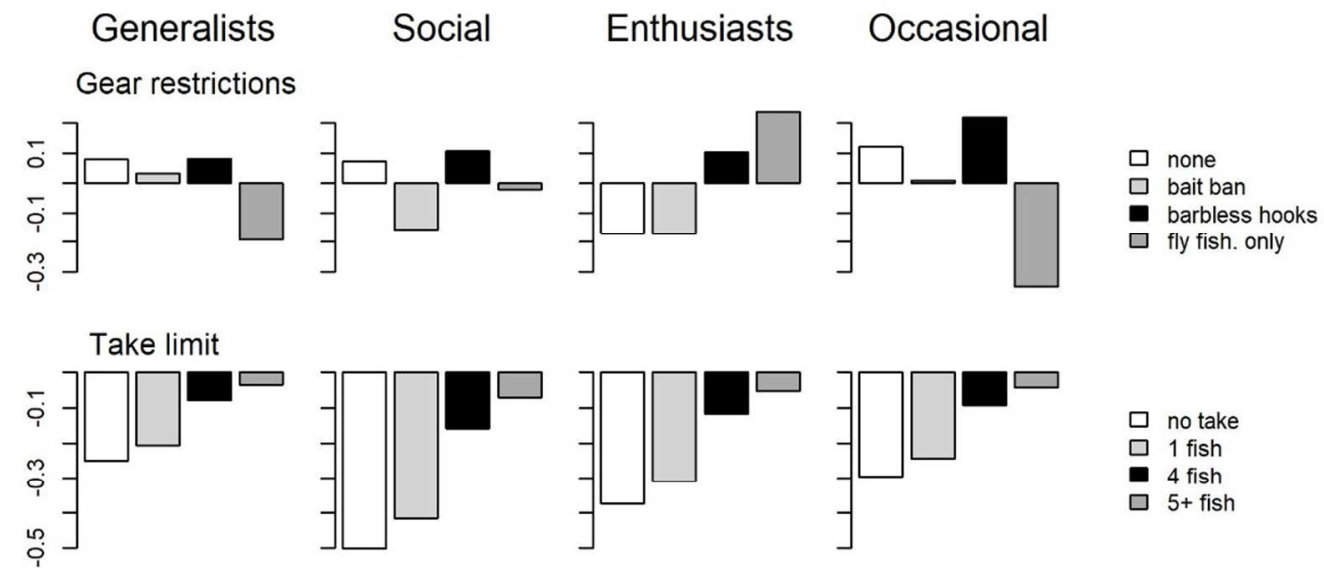

$$
\begin{aligned}
& \square \text { no take } \\
& \square 1 \text { fish } \\
& \text { ․ } 4 \text { fish } \\
& \square 5 \text { fish }
\end{aligned}
$$
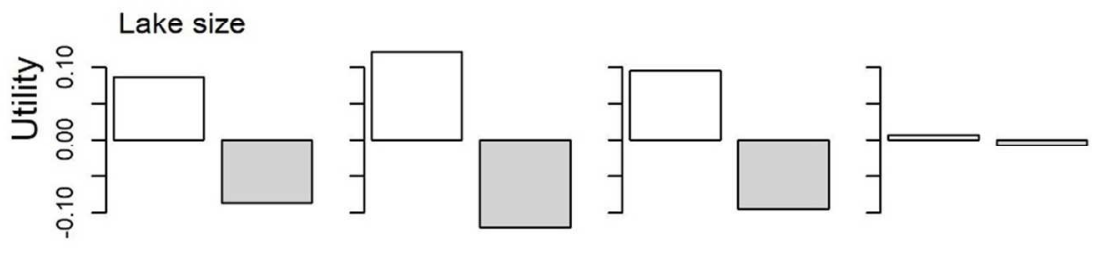

$\square<50$ ha

$\square>50 \mathrm{ha}$
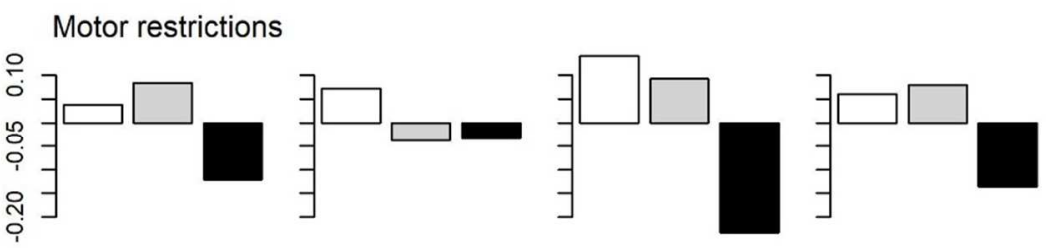

$\square$ any

$\square$ less than $10 \mathrm{hp}$

- electric only

1103

\section{Boat restrictions}
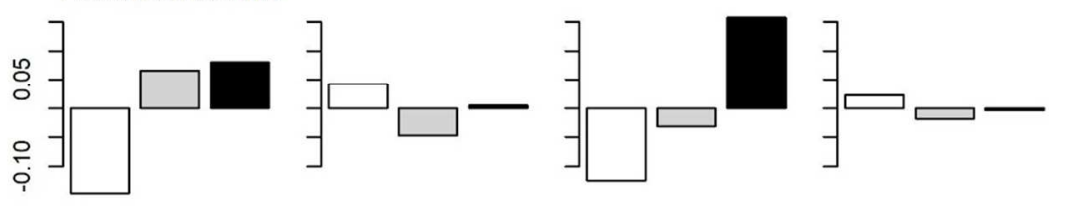

$\square$ no boats

$\square$ car top

trailer 


\section{$1104 \quad$ Figure 5}

1105

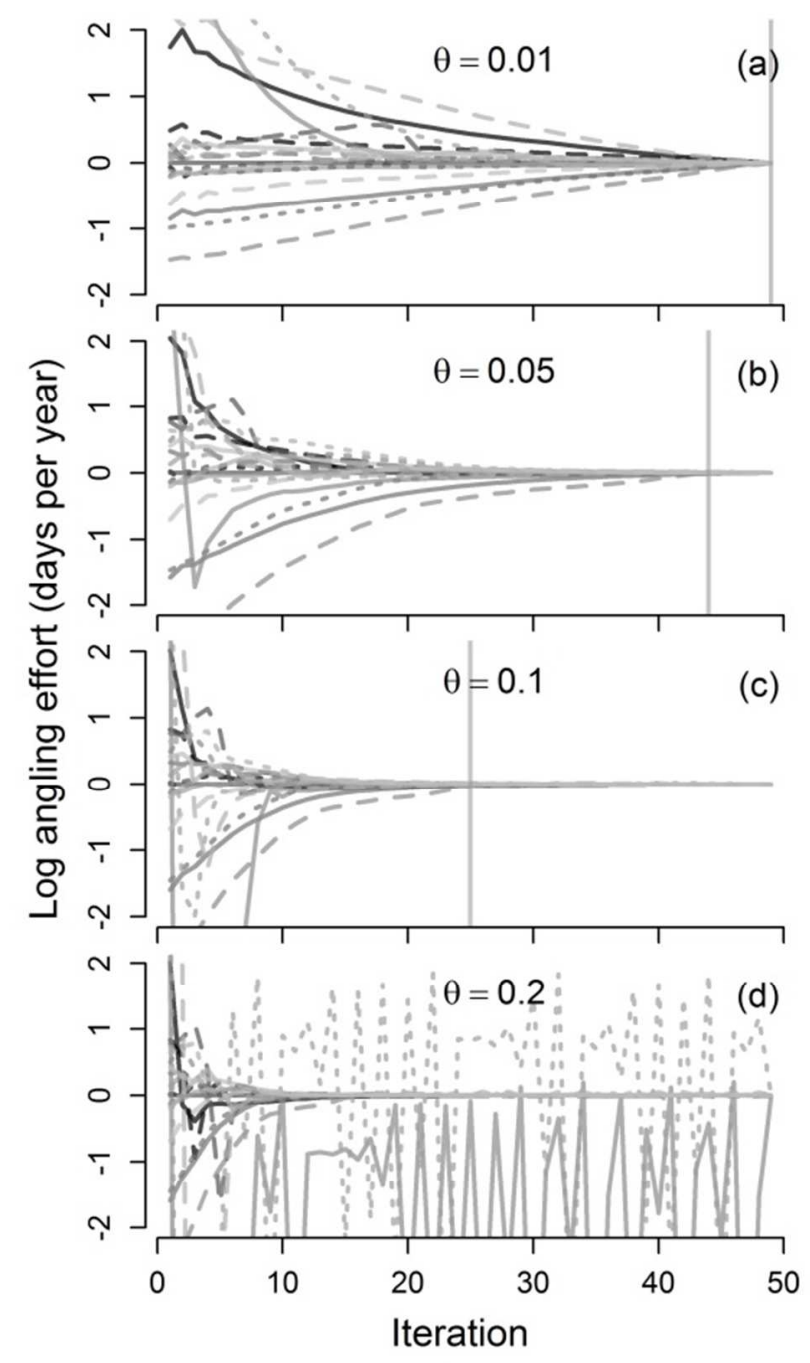

1106

1107 
1108 Figure 6
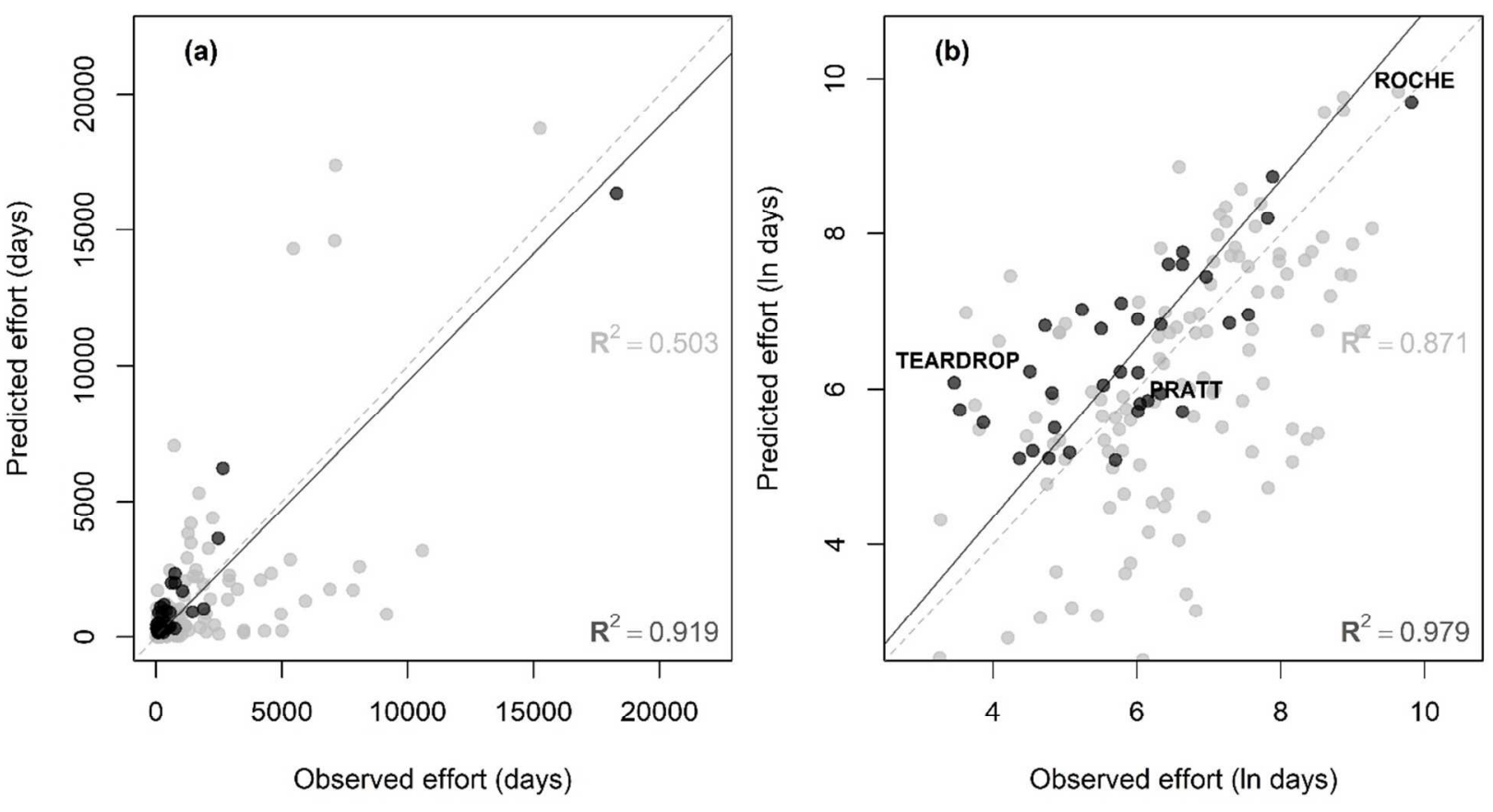

1109

1110 


\section{$1111 \quad$ Figure 7}

1112

(a) Kestrel Lake

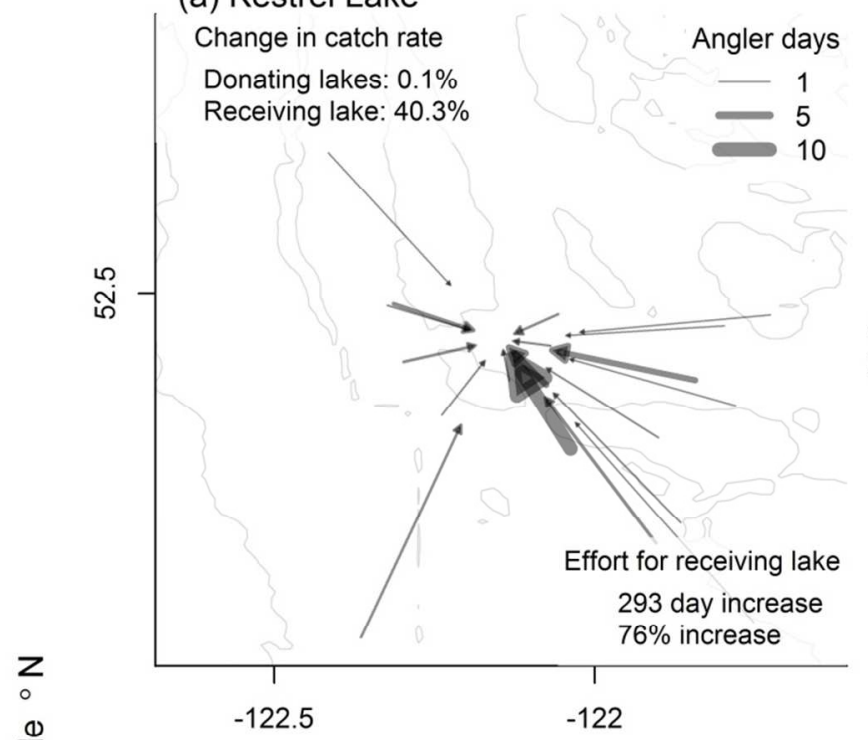

(c) Location of lakes

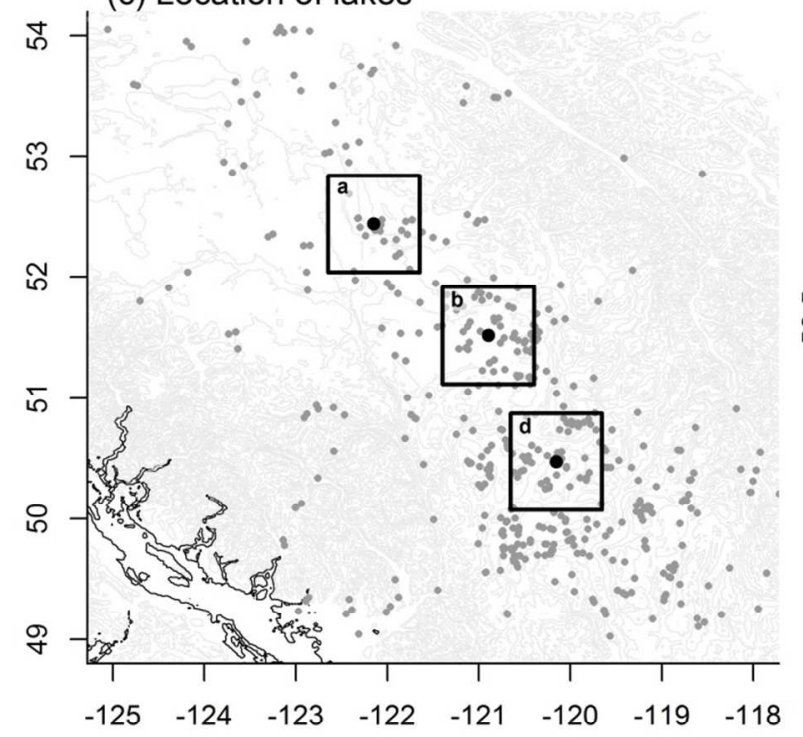

(b) Sheridan Lake

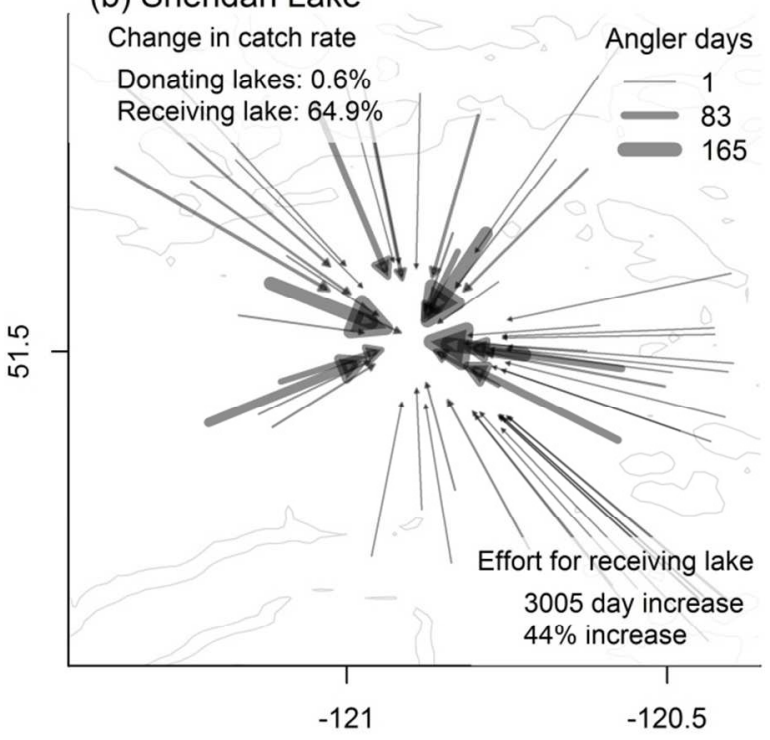

(d) Roche Lake

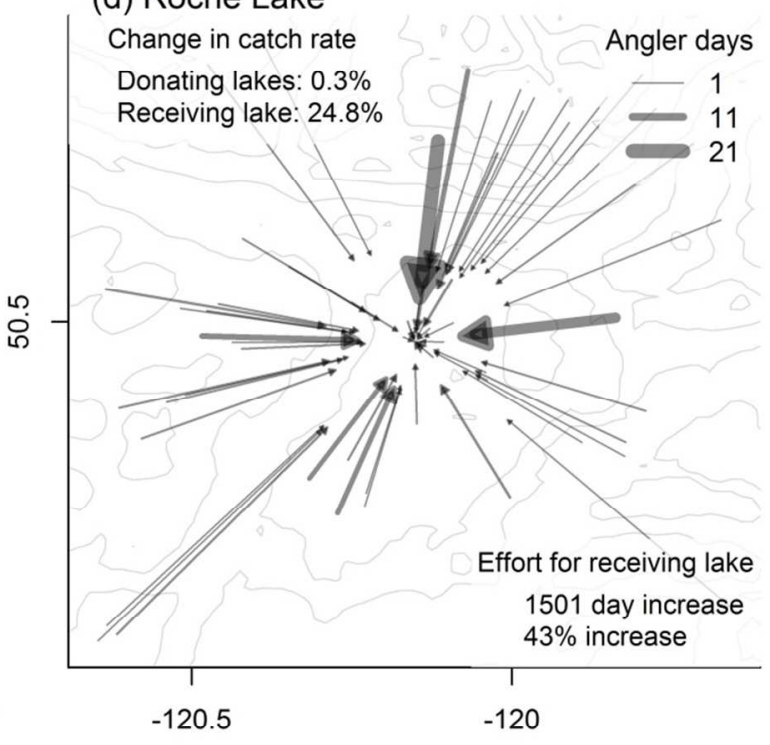

1113

Longitude ${ }^{\circ} \mathrm{W}$

1114 


\section{$1115 \quad$ Figure 8}

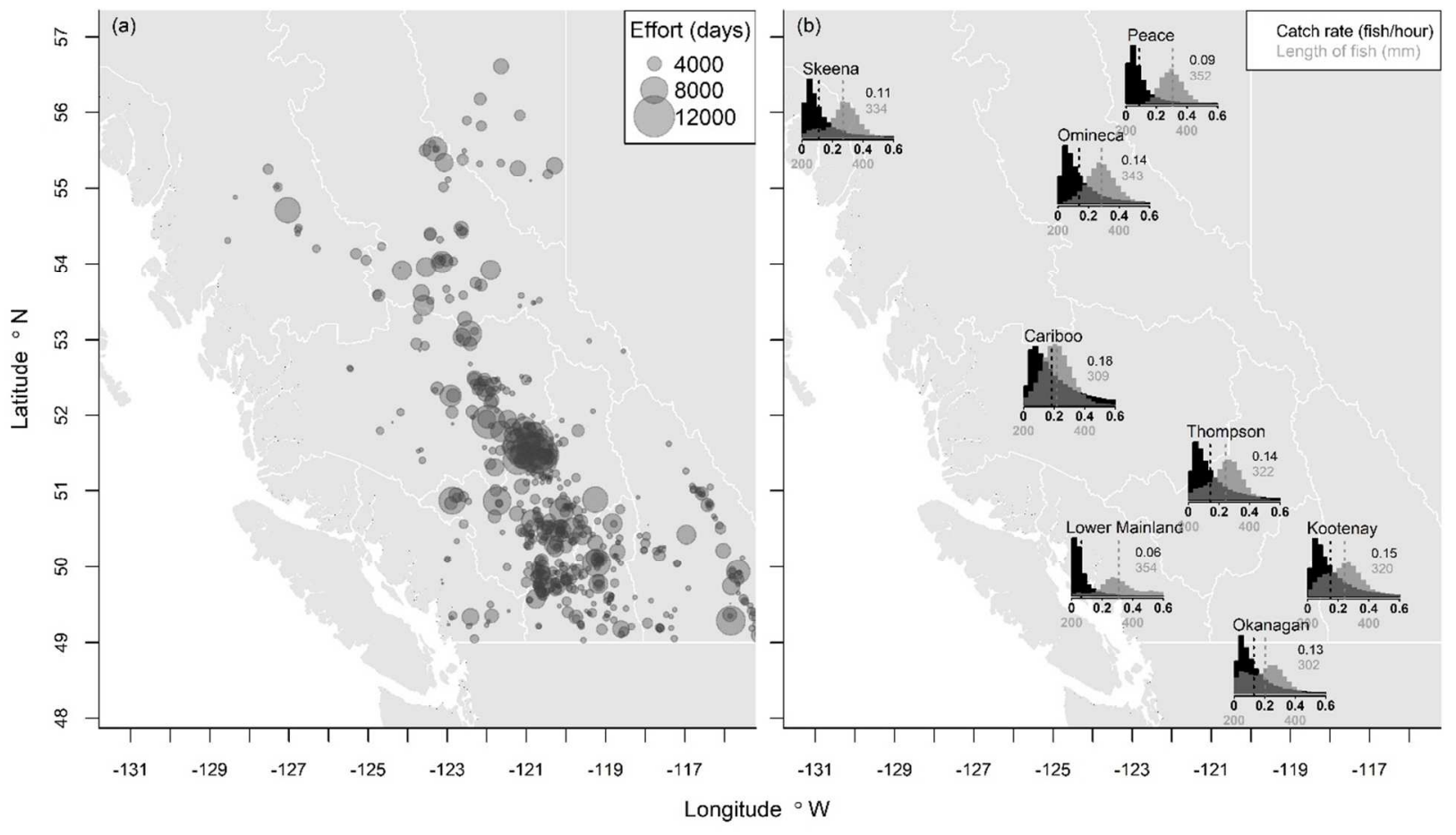

1116

1117 


\section{$1118 \quad$ Figure 9}
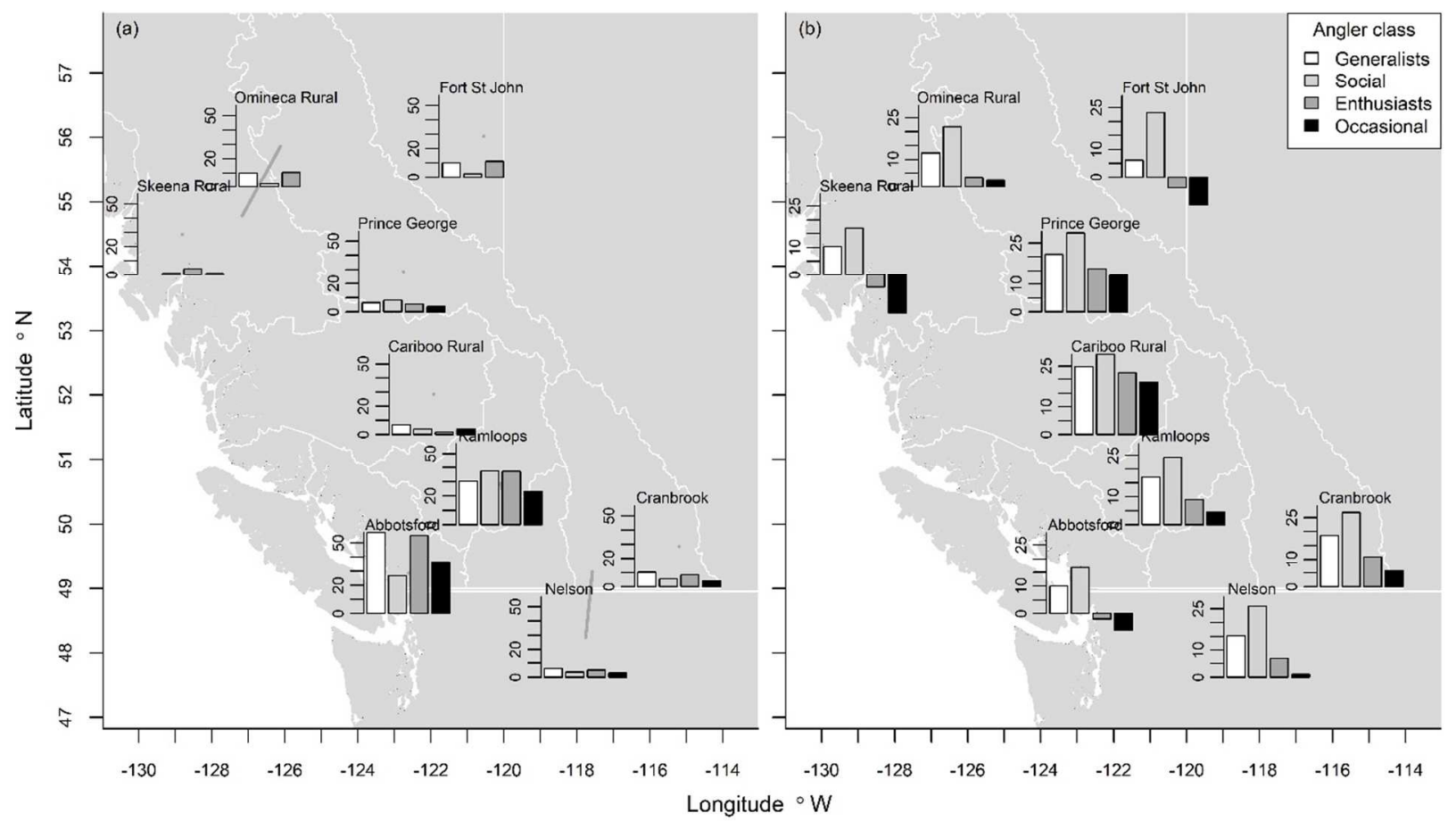

1119

1120 


\section{$1121 \quad$ Figure 10}

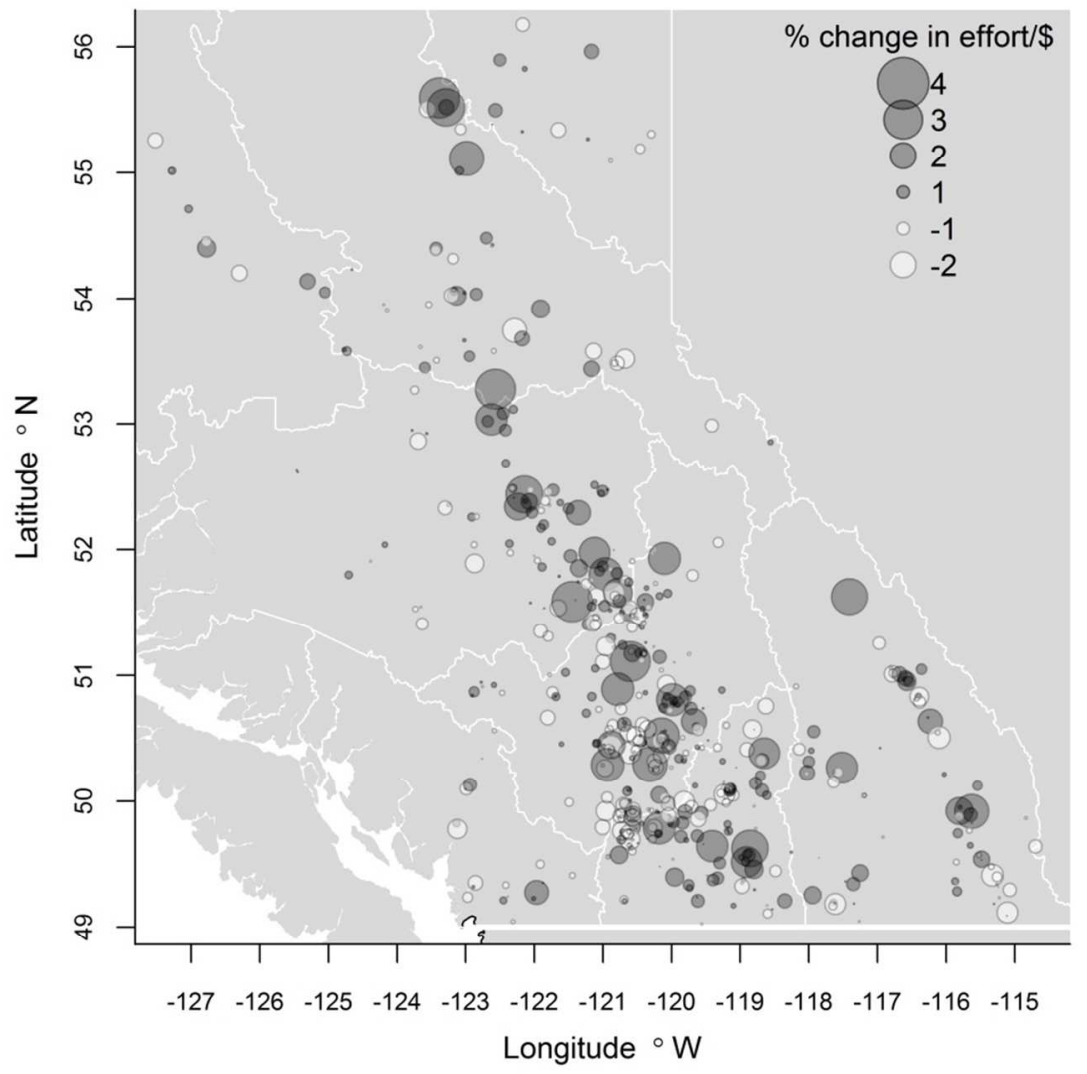

1122

1123 


\section{$1124 \quad$ Figure 11}
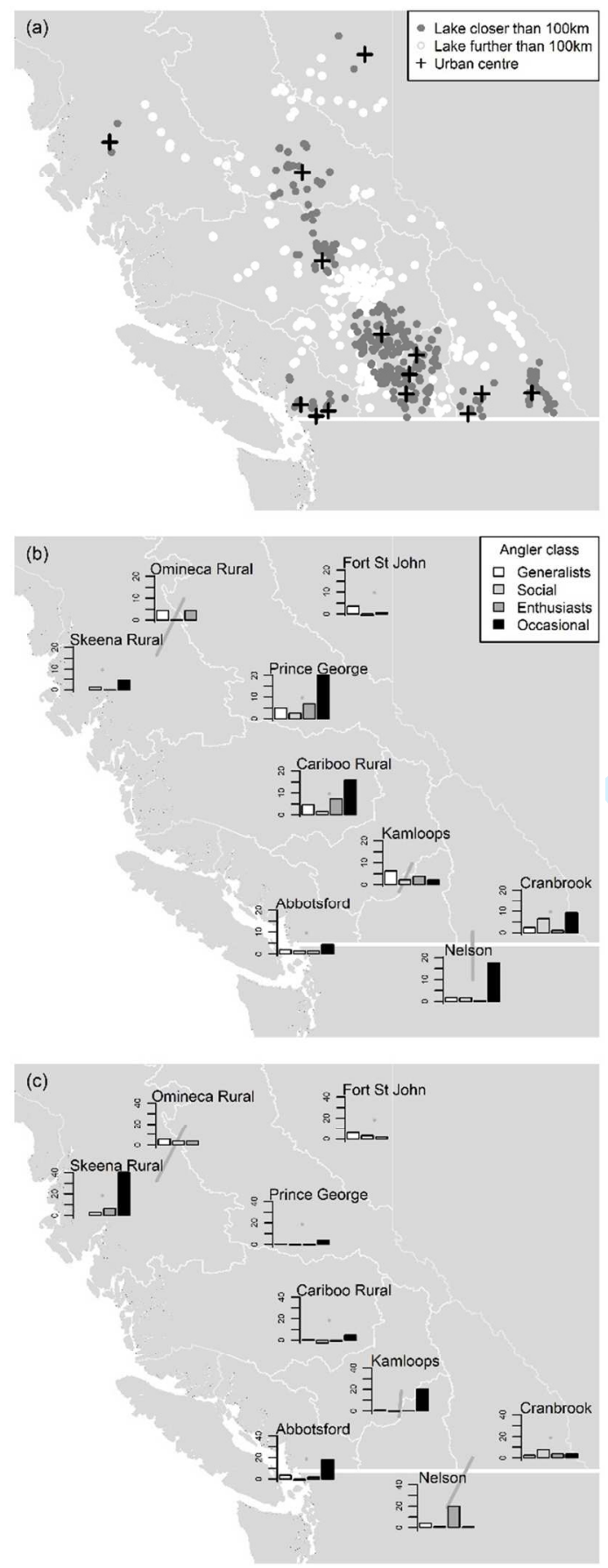

1125

1126 


\section{$1127 \quad$ Figure 12}
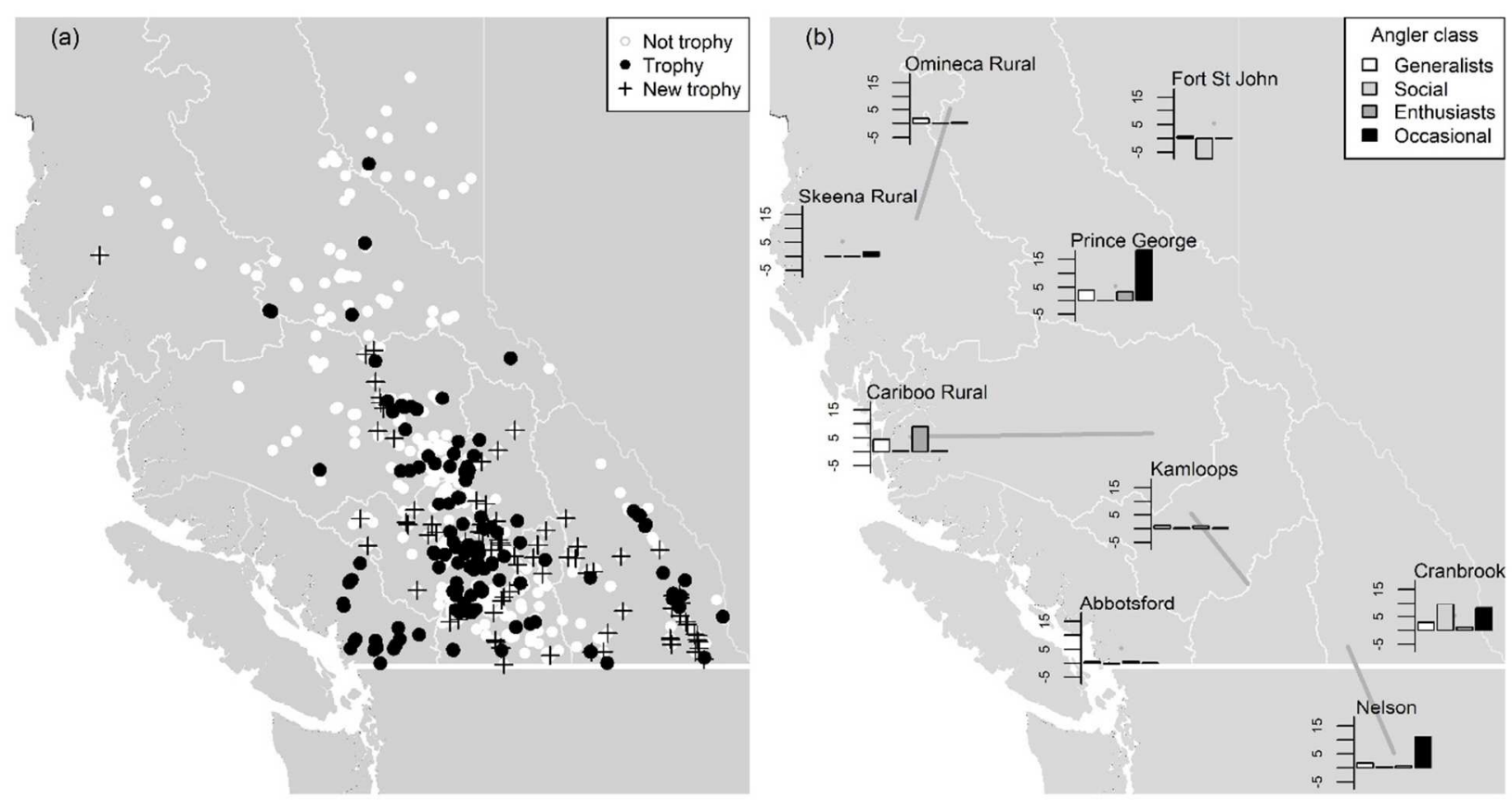